\title{
Application of observation operators for field scale soil moisture averages and variances in agricultural landscapes
}

\author{
Eunjin Han ${ }^{1}$, Gary C. Heathman ${ }^{2}$, Venkatesh Merwade ${ }^{3 *}$ and Michael H. Cosh ${ }^{4}$
}

\footnotetext{
${ }^{1}$ Graduate Research Assistant, School of Civil Engineering, Purdue University, West Lafayette, IN

${ }^{1}$ Current affiliation: Science Systems and Applications, Inc., USDA-ARS, Hydrology and Remote Sensing Laboratory, Beltsville, MD; email: Eunjin.Han@ars.usda.gov

${ }^{2}$ Soil Scientist, USDA-ARS, National Soil Erosion Research Laboratory, West Lafayette, IN; email: Gary.Heathman@ars.usda.gov

${ }^{3}$ Assistant Professor, School of Civil Engineering, Purdue University, West Lafayette, IN;

Corresponding author; e-mail: vmerwade@purdue.edu

4 Hydrologist, USDA-ARS, Hydrology and Remote Sensing Laboratory, Beltsville, MD; email: Michael.Cosh@ars.usda.gov
} 


\begin{abstract}
Scale difference between in situ and remotely sensed soil moisture observations and model grid size has been an issue for validation of remote sensing data, soil moisture data assimilation and calibration of hydrologic models. This study aims to link two different scales of soil moisture estimates by upscaling single point measurements to field averages for representing field-scale agricultural areas ( 2 ha) located within the Upper Cedar Creek Watershed in northeastern Indiana. Several statistical methods, mainly focusing on cumulative distribution function (CDF) matching, are tested to upscale point measurements to spatially representative soil moisture. These transforming equations are termed observation operators. The CDF matching is found to be the most successful upscaling method followed by the mean relative difference method using temporally stable point measurements. This study also tests the temporal and spatial (horizontal and vertical) transferability of the different observation operators. Results indicate that the two observation operators from the CDF matching approach and the mean relative difference method using a temporally stable location are transferable in space, but not in time. Rainfall characteristic is most likely the dominant factor affecting the success of observation operator transferability. In addition, the CDF matching approach is found to be an effective method to deduce spatial variability (standard deviation) of soil moisture from single point measurements.
\end{abstract}

Key words: Soil Moisture; upscaling, cumulative distribution matching, Cedar Creek, Indiana 


\section{Introduction}

Soil moisture is a key variable in understanding the hydrologic processes and energy fluxes at the land surface. In spite of new technologies for in situ soil moisture measurements, and increased availability of remotely sensed soil moisture data, scaling issues between soil moisture observations and model grid sizes pose a problem for full utilization of the available data (Western et al., 2002; Robinson et al., 2008; Verstraeten et al., 2008). For example, the scale of point measurements (support area less than $1 \mathrm{~m}^{2}$ ) typically does not match the size of model grids metrics for soil moisture data assimilation in providing observation error parameters, land surface modeling applications, and in the validation of remotely sensed soil moisture products (Charpentier and Groffman, 1992). The relationship between variance and mean has been investigated in several studies showing that the trend of the relationship may differ depending on the particular study (Famiglietti et al., 1999; Brocca et al., 2007; Famiglietti et al., 2008). As Vachaud et al. (1985) suggested, it would be very attractive if we could determine variances of soil moisture within an area by measuring soil moisture only at certain locations without dense sampling.

Efforts to obtain the spatially representative soil moisture mean and variance from a few sampling points were initiated by Vachaud et al. (1985) using the concept of temporal stability. Temporal stability studies have gained considerable attention in the context of validation of remotely sensed soil moisture products and have been applied to a range of spatial scales, different measurement depths and various time scales (Mohanty and Skaggs, 2001; Cosh et al., 2004; Cosh et al., 2006; Starks et al., 2006; Choi and Jacobs, 2008; Heathman et al., 2009; Joshi et al., 2011; Brocca et al., 2012). Temporal stability of soil moisture conditions is affected by many factors including topography, soil texture, vegetation and precipitation (Grayson and Western, 1998; Mohanty and Skaggs, 2001; Joshi et al., 2011). Therefore, it is uncertain as to whether a temporally 
stable location maintains its rank across time and space or if the rank of surface soil moisture measurements is consistent with time-stable observations at deeper depths in the profile.

Grayson and Western (1998) noted that temporally stable sites having a non-zero mean relative difference could be used to represent field average soil moisture provided that the offset 5 between the mean value and the non-zero time-stable locations were known. Although temporally stable field sites can be determined, in reality, there are cases where it is not feasible to install permanent soil moisture sensors at these locations for long-term monitoring. For example, in agricultural fields such as those in this study, permanent soil moisture sensors are installed near the boundary of a field in order not to impede landowner agricultural practices such as crop planting, harvesting, spraying and tillage operations. Therefore, it is necessary to investigate how well soil moisture observations from the permanent sensors represent field average conditions and how to transform the data to obtain representative information of the field soil moisture variability.

De Lannoy et al. (2007) explored several statistical methods to upscale point measurements to a field average soil moisture. They concluded that cumulative distribution function (CDF) matching and a simple linear relationship were the most successful upscaling methods to obtain the field average. They also identified converting equations or parameters from those methods to scale up observations from a specific point to the field average. The converting equations or parameters were termed observation operators according to Drusch et al. (2005). However, the work of De Lannoy et al. (2007) has some limitations for practical applications because they did not test if the observation operators can be transferrable in time or to other similar or adjacent sites.

This study aims to link two different scales of soil moisture estimates by upscaling single point soil moisture measurements to field average for representing field-scale agricultural watersheds ( 2 ha) located within the Upper Cedar Creek Watershed (UCCW) in northeastern Indiana. Estimation of field average soil moisture from point measurements can be utilized for calibration and validation of field-scale hydrologic models such as the Root Zone Water Quality Model. Since field-scale deterministic models can incorporate complicated soil-water-plant interaction processes from laboratory and field studies, they have provided a fundamental basis for watershed-scale hydrologic, water quality and agricultural system models (Abrahamson et al., 2006). In addition, several previous studies have shown great potential in using surface soil moisture data assimilation with one-dimensional hydrologic models at the field scale to provide 
al., 2003; Han et al., 2011). Therefore, this upscaling approach is a prerequisite for successful data assimilation applications at the field scale by providing more accurate, less biased field representative soil moisture observations.

A couple of methods are investigated in this study to deduce the soil moisture field average and variance from single point measurements, especially focusing on the CDF matching method which has been shown to be an effective bias correction or rescaling method in many geophysical studies as explained in Section 4.1. The main objectives of this study are: 1) to find appropriate way(s) for upscaling point soil moisture measurements to field averages by comparing different observation operators, 2) to explore whether the observation operators are transferable in time and space (between different fields and between different soil layers), 3) to determine the most influential factors affecting the temporal or spatial transferability of the observation operators, and 4) to estimate spatial variability (standard deviation) of soil moisture within the study areas using the point measurements and the CDF matching method.

Overall, this study provides an alternate means for overcoming the scale differences between in situ point scale soil moisture measurements and coarse resolution remote sensing observations. The two field study sites in this research work, AS1 and AS2, have permanent soil moisture sensors installed near the outlet of the field scale watershed. The permanent sensors are part of the soil moisture monitoring network in the UCCW which will be included in the validation program for soil moisture products from the upcoming (2014) NASA Soil Moisture Active/Passive Mission (SMAP). Therefore, it is expected that this study is an initial step in resolving the scaling issue between in situ point measurements and the remote sensing grid, thus improving efforts in the calibration and validation of space-borne operational products.

In Section 3, limitations in applying temporal stability analysis as a method to obtain spatially representative values are discussed based on previous studies by Heathman et al. (2012) and Heathman et al.(in press) which used the same datasets from the same field sites as the present study. By addressing the limitations of temporal stability analysis which has been widely applied in literature(Cosh et al., 2004; Martinez-Fernandez and Ceballos, 2005; Cosh et al., 2006; Heathman et al., 2009; Joshi et al., 2011), this study aims to advance our ability to more adequately obtain spatially representative near-surface soil moisture estimates. 


\section{Study area and data measurements}

Soil moisture observations for this study were collected at two small agricultural watersheds, AS1 (2.23ha) and AS2 (2.71ha) that are located in the Upper Cedar Creek Watershed (UCCW) in northeastern Indiana (Figure 1). The two watersheds have permanent soil moisture sensors and weather stations installed as part of an environmental monitoring network in the UCCW established by the United States Department of Agriculture, Agricultural Research Service (USDA-ARS) National Soil Erosion Research Laboratory (NSERL). The monitoring network was initiated in 2002 by the Source Water Protection Project and the Conservation Effect Assessment Project, and are planned to be used for the validation of upcoming NASA SMAP soil moisture products as one of the validation sites. For more detailed information regarding the UCCW environmental monitoring network, please see Flanagan et al. (2008).

Both AS1 and AS2 were planted in soybeans in 2009 and corn in 2010. The two fields have different management practices; AS1 is in no-till, with AS2 having rotational tillage in years when corn is planted. The slope of the fields ranges from 5 to $10 \%$. Major soil types in each field are a Glynwood (GnB2) silt loam (Fine, illitic, mesic Aquic Hapludalfs) and a Blount (BaB2) silt loam (Fine, illitic, mesic, Aeric Epiaqualfs) for AS1 and AS2, respectively (Figure 1).

Temporary spatial soil moisture measurements were obtained during the summers of 2009 and 2010 between the last crop spraying and harvest so as not to interfere with landowner agricultural operations. Twenty temporary soil moisture sensors, with $35 \mathrm{~m}$ grid spacing, were installed across the watersheds at the surface $5 \mathrm{~cm}$ depth in 2009 , and two sensors at two depths $(5 \mathrm{~cm}$ and $20 \mathrm{~cm})$ were installed, with a 70m grid spacing, at ten locations in each field in 2010 (Figure 1). The 2010 sensor locations were coincident with the 2009 locations based on 70m spacing. Some of the temporary sensors in 2009 did not function properly because of data transmission errors. Therefore, 18 and 15 point measurements out of 20 sensors were obtained in 2009 for AS1 and AS2, respectively. Also due to data transmission errors, AS2 did not report data at several sites in August and September of 2009. Therefore, AS2 had a shorter measurement period from July 16 to August 8 in 2009. However, measurements were obtained in AS1 from July 15 to September 21, 2009. In 2010, after modifications in data transmission technology, soil moisture was spatially measured from June 30 to September 21 from all ten temporary sensor locations in AS1 and AS2. Although the total number of observations for each dataset may not seem sufficient to obtain robust spatial 
statistical results, this study assumes that spatially distributed sensor locations can provide soil moisture characteristics across the fields.

The permanent soil moisture sensors are located near the outlet of the two watersheds. They provide soil moisture measurements at four different depths $(5 \mathrm{~cm}, 20 \mathrm{~cm}, 40 \mathrm{~cm}$ and $60 \mathrm{~cm})$ every 10 minutes. The temporary sensors measured soil moisture every 30 minutes at 5 and $20 \mathrm{~cm}$ depths and transmitted to a field data logger. The original 10 minute measurements from the permanent sensors were subset so that they would match the temporary sensor 30-minute measurements. Out of four different measurement depths from the permanent sensors, only $5 \mathrm{~cm}$ and $20 \mathrm{~cm}$ measurements were used in combination with the temporary sensor measurements for data analysis of this study.

Soil moisture sensors used for this study were Stevens Water SDI-12 Hydra Probes, a type of frequency domain reflectometry measuring soil water content based on changes in soil dielectric permittivity. More details regarding the accuracy of the soil moisture measurements, sensor calibrations and soil properties information can be found in Han et al. (2011) and Heathman et al. (2012).

\section{Related work - temporal stability analysis}

The work in this investigation is an extension of two previous studies that involved a comprehensive analysis of temporal stability conducted in two agricultural fields (AS1 and AS2) to determine whether measurements of soil moisture data from permanent sensor locations (edgeof-field) could be used to adequately represent actual field averages that were obtained from a number of temporary "in-field" sensors (Heathman et al., 2012; Heathman et al., in press). The previous studies found that sensor measurement locations do not necessarily maintain their rank in temporal mean of relative difference (MRD) for different time periods and depths (Figure 2). Nonetheless, most sensors consistently overestimated (positive MRD) or underestimated (negative MRD) the field averages for two different years with some exceptions. In regards to consistency of rank in MRD between two different depths $(5 \mathrm{~cm}$ vs. $20 \mathrm{~cm})$, the majority of sensor locations in field AS2 maintained their consistency in having positive or negative MRD. However, five (\#4, \#6, \#8, \#12 and \#16) out of eleven sensors at AS1 had opposite signs of MRD, which means that they overestimated the field average at surface and underestimated it at the $20 \mathrm{~cm}$ depth, or vice versa. 
According to the results in the two previous studies there were no single measurement locations found to represent field average soil moisture conditions from one year to the next or for two different soil layers at both AS1 and AS2. In addition, the most time-stable sites do not remain the same for different years (e.g. \#17 in 2009 and \#8 in 2010 for 5cm data at AS1) and different depths (e.g. \#8 for $5 \mathrm{~cm}$ and \#19 for $20 \mathrm{~cm}$ at AS1 in 2010) as shown in Figure 2. Several other studies investigated temporal stability at multiple soil depths found it difficult to determine one representative location for all soil layers (Starks et al., 2006; De Lannoy et al., 2007; Heathman et al., 2009). Starks et al. (2006) compared the results of temporal stability analysis of soil moisture observations from two different remote sensing campaigns in the Little Washita river watershed, the Southern Great Plains 1997 (SGP97) and the Soil Moisture Experiment 2003 (SMEX03). They found that no single site represented the watershed soil moisture average consistently for any depth interval during the combined experiment periods. However, for the two agricultural fields in the present study, if we consider that one single location could be selected for practical purposes, then the second most temporally stable site may serve as a substitute for the primary site provided there is little statistical difference between the two sites. Then, sites \#19 and \#21 may be considered as temporally stable sites for AS1 and AS2, respectively, considering all data from two separate years and two different depths.

Although sites \#19 and \#21 are selected as the most temporally stable sites for AS1 and AS2, respectively, there are problems in estimating field averages from these sites using the constant offset approach mentioned earlier by Grayson and Western (1998). This is due to the signs of their respective constant offsets being opposite for the data in 2009 and 2010 (Figure 2). For example, \#19 at AS1 had a constant offset of -0.1003 in 2009 and 0.0586 in 2010, and \#21 at AS2 had values of -0.0368 in 2009 and 0.2061 in 2010. This indicates that they underestimated the field averages in 2009 and overestimated them in 2010. Moreover, \#21 at AS2 showed drastically different offset values in different years; it highly overestimated the field average (high offset value, 0.2061) in 2010 while maintaining a soil moisture value close to the field average (offset value close to zero, -0.0368) in 2009. This implies that the behavior of soil moisture may be influenced by several temporally varying factors and that it is necessary to adjust observations from the temporally stable site for different time period. Even though they are considered to be the most temporally stable sites, they require different offset values for each year in order to adequately estimate field averages. Therefore, for the dataset in the present study, the constant offset approach adopted by Grayson 
and Western (1998) is not appropriate to obtain field average soil moisture from the temporally stable site. This fact places limitations on the practical applications of temporal stability analysis for upscaling point soil moisture measurements to field averages since additional spatial samplings are still required to estimate the offset values which need to be updated for different time periods.

5 Thus, we must reconsider whether the temporal stability approach can achieve its original purpose: minimizing the numbers of point observations to characterize the spatiotemporal variability of soil moisture.

8 There are few papers in the literature where investigations validated the results for temporal stability analysis. For example, Martinez-Fernandez and Ceballos (2005) analyzed the temporal stability of soil moisture measured continuously for several years at two different scales. They carried out calibration and validation of the analysis for different time periods and concluded that representative mean soil moisture values could be obtained reliably from a temporally stable location irrespective of scale (area of $1285 \mathrm{~km}^{2}$ and $0.62 \mathrm{~km}^{2}$ ), land cover (cropped and forested) and temporal sampling (fortnightly and hourly). Martinez-Fernandez and Ceballos (2003) also found consistent results for the same representative location after applying temporal stability analysis for three discrete years, as well as for the entire period of measurements. One of the interesting results from Martinez-Fernandez and Ceballos (2005) was that the minimum sampling period necessary to determine the representative site through temporal stability analysis was approximately one year covering a complete seasonal cycle. Different types of soil moisture sensor observations in our study compared to those in Martinez-Fernandez and Ceballos (2005), shortterm measurements for multiple years, reinstallation of sensors each year and shallow observation depth $(\sim 5 \mathrm{~cm})$ might be reasons for the variability in temporal stability results in our study. However, permanent sensor measurements also showed similar variability in the results from year to year. Considering the high cost involved with measuring soil moisture continuously over extended time periods and the effect of frozen soil during winter conditions, further research is necessary to assess the validity of temporal stability analysis conducted for short-term soil moisture measurements.

In addition, the previous studies which validated temporal stability results for other time periods used soil moisture from relatively deep in the soil profile (e.g. $30 \sim 150 \mathrm{~cm}$ in Grayson and Western (1998) and $1 \mathrm{~m}$ in Martinez-Fernandez and Ceballos (2005)). Considering the shallow sensing depth $(\sim 5 \mathrm{~cm})$ of remotely sensed soil moisture products and higher variability of soil moisture in 
to surface soil moisture measurements in the context of validating remotely sensed soil moisture retrievals.

Most of the previous studies conducting temporal stability analysis across different scales and depths did not attempt to validate the most temporally stable sites for different time periods, considering differences in vegetation type and rainfall amounts that could occur over time. For instance, the Corn Belt region in the Midwestern United States typically rotates crops between corn and soybean every year or every two years. Therefore, the effect of different crop types (or other factors which temporally vary and affect the stability of soil moisture conditions) should be accounted for in determining temporally stable sites for the purpose of validating long-term remote sensing soil moisture retrievals or in evaluating long-term hydrologic model predictions.

As we have noted, the application of temporal stability analysis has received considerable attention for investigating soil moisture variability and in validating remotely sensed soil moisture data (Mohanty and Skaggs, 2001; Cosh et al., 2004; Cosh et al., 2006; Starks et al., 2006; Choi and Jacobs, 2008; Heathman et al., 2009; Choi and Jacobs, 2011; Joshi et al., 2011). However, aforementioned limitations of the temporal stability analysis (uncertain possibilities of finding a single representative location for different periods and different soil layers, and uncertainty in the transferability of offset constants in time and space) still remain obstacles in practical applications using the temporal stability approach. Due to limitations involving temporal stability studies, De Lannoy et al. (2007) suggested that certain transformation functions or upscaling of point measurements may offer a viable way to obtain spatial averages within a satellite pixel or a model grid cell in order to limit the representativeness error of point measurements. Thus, the CDF matching method, an alternative upscaling method, is tested in the present study as a possible means for obtaining temporally and spatially transferrable observation operators

\section{Methodology}

As Figures 3 and 5 illustrates, soil moisture observations from the permanent sensors do not represent the field average appropriately in either field. Even though the permanent sensor measurements and the field averages are generally in agreement with the rainfall dynamics, their relationships are complicated. For example, the AS1 permanent sensor overestimated the field averages for the first half of the experiment period and underestimated them during September, 2009 (Figure 3 (a)). Given these problems with the permanent sensor measurements, it would be 
desirable to transform the soil moisture observations from the permanent sensors so that they match the field averages. This transformation can be achieved using observation operators (Drusch et al., 2005). This section explains the different observation operators used in this study to estimate field averages and standard deviations of soil moisture.

\subsection{Estimation of field averages} CDF matching method

In this study, the cumulative distribution function (CDF) matching method is the primary approach used for estimating field averages based on point soil moisture measurements from the permanent sensors. The CDF matching method has been used in many geophysical studies for the purpose of bias correction or rescaling of different sets of observations. For example, the concept of CDF matching was applied for rainfall estimation, specifically to adjust the relationships between reflectivity and rain rate (Atlas et al., 1990) and to quantify uncertainties in satellite rainfall retrievals (Anagnostou et al., 1999). Wood et al. (2002) also used a similar approach to correct biases in model forecasted rainfall and temperature for long-range hydrologic forecasting. With regard to soil moisture variables, Liu et al. (2009) and Liu et al. (2011) merged soil moisture retrievals from different satellites after rescaling them by the CDF approach. Reichle and Koster (2004) and Drusch et al. (2005) adopted the CDF method to define observation operators for rescaling satellite-based soil moisture observations into model climatology. In a field scale soil moisture study, De Lannoy et al. (2007) used the CDF matching method as one of the upscaling methods to estimate field averages from point soil moisture measurements. While Liu et al. (2009) and Liu et al. (2011) defined different scaling linear equations for separate percentile segments of CDF curves, Drusch et al. (2005) and De Lannoy et al. (2007) derived a polynomial equation for their entire dataset. In the present study, the same approach as Drusch et al. (2005) is adopted to find appropriate observation operators.

The CDF matching method is used to adjust the CDF curve of one variable to the curve of another reference variable. In this study, the CDF curves of the point measurements are scaled to those of the field averages (Figure 4). Higher order moments of point measurement distribution functions, including mean, standard deviation and skewness, can be corrected through the CDF matching method. Procedures for the CDF matching method are summarized below.

1) Rank the two datasets of permanent sensor measurements $\left(\theta_{p}\right)$ and the field average $\left(\theta_{m}\right)$. 
2) Compute differences between each corresponding element from the ranked datasets

$$
\tilde{\theta}_{d, i}=\tilde{\theta}_{m, i}-\tilde{\theta}_{p, i}
$$
where $\tilde{\theta}_{m, i}$ and $\tilde{\theta}_{p, i}$ are the ranked field averages and point measurements, respectively, for $i=1 \ldots n$, where $n$ is the number of the measurements.

3) Find an optimum polynomial fit to the ranked point measurements and corresponding differences using the least square optimization. In this study, the third order polynomial fit was chosen for all datasets according to De Lannoy et al. (2007) and the principle of parsimony.

$$
\hat{\tilde{\theta}}_{d, i}=a_{0}+a_{1} \tilde{\theta}_{p, i}{ }^{3}+a_{2} \tilde{\theta}_{p, i}{ }^{2}+a_{3} \tilde{\theta}_{p, i}
$$

where $\widehat{\tilde{\theta}}_{d, i}$ is the estimated difference for $\tilde{\theta}_{d, i}$

4) Compute the estimated field average from the estimated difference.

$$
\hat{\tilde{\theta}}_{m, i}=\hat{\tilde{\theta}}_{d, i}+\tilde{\theta}_{p, i}
$$

The polynomial equation (Equation 2) is the observation operator for each dataset and is used to remove the systematic differences between the point soil moisture measurements and the field averages.

\section{Other upscaling methods}

Besides the CDF matching method, other linear transformation methods are applied to find the best observation operators. First, a simple linear relationship between point measurements from the permanent sensors and field averages is used. This method is designated as LR hereafter.

$$
\hat{\theta}_{m, i}=b_{0}+b_{1} \theta_{p, i}
$$

where $\hat{\theta}_{m, i}$ is the estimated field average corresponding to permanent sensor measurements $\left(\theta_{p, i}\right)$ at time $i$.

The second alternative method is to use the point measurements from the most temporally stable site and a constant offset $\left(\bar{\delta}_{j}\right)$ obtained from the temporal stability analysis as Grayson and Western (1998) introduced in order to estimate field averages from single point measurements.

$$
\hat{\theta}_{m, i}=\frac{\theta_{s t, i}}{1+\bar{\delta}_{j}}
$$

where $\theta_{s, t}$ is soil moisture measurements from the temporally stable site at time $i$. The constant offset $\left(\bar{\delta}_{j}\right)$ is a temporal mean of relative difference from the temporally stable site $(j)$, defined by Vachaud et al. (1985). 


$$
\bar{\delta}_{j}=\frac{1}{n} \sum_{i=1}^{n} \frac{\theta_{j, i}-\theta_{m, i}}{\theta_{m, i}}
$$

where $\theta_{m, i}$ is an average (mean) of spatially distributed $k$ point measurements at time step $i$ $\left(\theta_{m, i}=\frac{1}{k} \sum_{j=1}^{k} \theta_{j, i}\right)$ and $n$ is the total number of the temporal measurements (time step). This method is designated as MRD-ST hereafter.

The mean relative difference approach has been applied in several previous studies to find representative field average values once the temporally stable site, having a non-zero mean relative difference, is found (Grayson and Western, 1998; Starks et al., 2006; Heathman et al., 2012). However, even though one of the temporary sensors in this study is found to be the most temporally stable site, the information from the site cannot be used for long-term monitoring because the sensor equipment must be removed from the field after the experiment period to allow landowner farming operations to continue. Therefore, the mean relative difference method using the permanent sensor measurements, instead of the "in-field" temporally stable site, is also tested as a third alternative observation operator.

$$
\hat{\theta}_{m, i}=\frac{\theta_{p, i}}{1+\bar{\delta}_{p}}
$$

where the constant offset $\left(\bar{\delta}_{p}\right)$ is a temporal mean of relative difference from the permanent sensor measurements defined as Equation 6. This method is designated as MRD-P hereafter.

Even though the mean relative difference approach can predict field averages with high correlation coefficients, as shown in Starks et al. (2006), it does not guarantee unbiased estimation. In addition, the amplitude of the estimated field average will be smaller than that of the actual soil moisture measurement if the mean relative difference is positive, and the amplitude will be larger if the difference is negative, due to the multiplicative relationship (De Lannoy et al., 2007). In order to avoid these problems of the mean relative difference approach, absolute difference relationship is also used based on the additive relationship, as a fourth alternative observation operator.

$$
\widehat{\theta}_{m, i}=\theta_{p, i}-\bar{\delta}_{a, p}
$$

where $\bar{\delta}_{a, p}$ is a temporal mean of absolute differences between the permanent sensor measurements $\left(\theta_{p, i}\right)$ and spatial averages $\left(\theta_{m, i}\right), \bar{\delta}_{a, p}=\frac{1}{n} \sum_{i=1}^{n}\left(\theta_{p, i}-\theta_{m, i}\right)$. Note that this difference is not normalized by the average as shown in Equation 6. This method is termed AMD 
hereafter.

\subsection{Estimation of standard deviation of spatial soil moisture observations}

The same principle of the aforementioned CDF matching method is applied to estimate standard deviations of soil moisture within the study areas using point measurements from the permanent sensors. Vachaud et al. (1985) used the concept of temporal stability to identify the value of one or two standard deviations, as well as the mean, based on the assumption that particular locations maintain their rank in the cumulative probability function for different observation times. In the present study, a hypothetical location is assumed to be a temporally stable site and to provide soil moisture differing from the mean by one standard deviation $\left(\theta_{h p, i}=\theta_{m, i}+\right.$ $\left.\sigma_{i}\right)$ consistently as shown in Figure $4(\mathrm{~b})$. The means $\left(\theta_{m, i}\right)$ and standard deviations $\left(\sigma_{i}\right)$ of soil moisture observations from the spatially distributed sensors are assumed to represent the true variability of the soil moisture in the watersheds. Using the mean and standard deviations obtained from all the sensors, the soil moisture time-series data for the hypothetical location $\left(\theta_{h p, i}\right)$ that represent consistently wet conditions (mean plus one standard deviation) are computed $\left(\theta_{h p, i}=\right.$ $\left.\theta_{\mathrm{m}, \mathrm{i}}+\sigma_{i}\right)$. Then, the same CDF matching procedures described in the previous section are repeated to compute $\hat{\theta}_{h p}$ by rescaling the permanent sensor measurements $\left(\theta_{p}\right)$ to $\theta_{h p}$ (Figure 4(a)). The third order polynomial equations are selected for observation operators again for consistency. Once $\hat{\theta}_{h p, i}$ is determined, the predicted standard deviation at time step ( $\left.\hat{\sigma}_{i}\right)$ is obtained by subtracting the field average $\left(\hat{\theta}_{m, i}\right)$ estimated by the CDF matching and the permanent sensor data (Equation 3).

$$
\hat{\sigma}_{i}=\hat{\theta}_{h p, i}-\hat{\theta}_{m, i}
$$

Figure 4 illustrates the concept of estimating the field averages and standard deviation using the CDF matching method.

\section{Results and discussion}

\subsection{Upscaling point measurements to field averages}

\section{Results of CDF matching method}

Figure 5 shows how the original CDF of permanent sensor measurements is adjusted to the CDF of field averages for each dataset of AS1 and AS2 (5cm in 2009, and 5cm and 20cm in 2010). 
In 2009, the permanent sensor at AS1 overestimated the field averages for some periods and underestimated them for other periods, whereas the permanent sensor at AS2 consistently overestimated the field averages (Figure 5 (a) and (b)). In 2010, permanent sensors at both AS1 and AS2 highly underestimated the field averages for both $5 \mathrm{~cm}$ and $20 \mathrm{~cm}$ depth measurements.

The observation operators were determined through least square fits of a third order polynomial with the coefficients listed in Table 2 . We found that the observation operators could be used to rescale the CDFs of point measurements to field averages successfully. Even though the relationships between ranked differences and ranked point observations from six datasets were very different from each other, the third order polynomial was consistently selected for observation operators in order to test their transferability between datasets (Figure 6). In addition, it was found that other higher order polynomial equations did not provide significantly improved fitting results.

Figure 6 shows that the observation operators were non-linear with the permanent point measurements for all datasets in the same manner that remotely sensed soil moisture observations were non-linear with the model predictions in Drusch et al (2005) and with the in situ soil moisture observations in Matgen et al., (2011). Systematic difference between the field averages and permanent sensor measurements varied significantly each year for both AS1 and AS2, as expressed in different shapes and ranges of the observation operators from 2009 and 2010 in Figure 6. The significant difference in observation operators from different years implies that there is a low possibility that the observation operators are temporally transferable. Temporal transferability is crucial from operational perspective for validation of future remote sensing data and application of data assimilation. Regarding the temporal transferability of observation operators using the CDF matching method, Matgen et al., (2011) showed that observation operators obtained for rescaling remotely sensed soil wetness index to in situ soil moisture measurements have similar shapes for two separate consecutive years. Drusch et al (2005) showed that the success of temporal transferability of observation operators in rescaling remotely sensed soil moisture products to modeled soil moisture varied according to the geographical region within the U.S. In the present study dynamic variations of the permanent sensors resulted in different observation operators in time.

Shapes of the observation operators for AS1 and AS2 are similar for the 2010 data, whereas they are very different for the 2009 data. In spite of having the same rainfall (the two field sites, AS1 and AS2, are only 500 meters apart) and crop types, their soil moisture variabilities are very 
different. This fact suggests high localized heterogeneity in these two fields, especially in 2009, which may affect spatial transferability of the observation operators. More details about possible factors affecting the ability to transfer observation operators spatially are discussed in later sections.

Soil moisture conditions at deeper depths are more stable than dynamically varying surface soil moisture due to the influence of atmosphere. Therefore, the datasets from the $20 \mathrm{~cm}$ sensors in 2010 show less non-linear relationships compared to the data for the $5 \mathrm{~cm}$ sensors for both AS1 and AS2. Even though the observation operators for the deeper depths appear linear for most of the soil moisture ranges, a high degree of non-linearity is associated with higher soil moisture values, which is consistent with highly variable and unstable soil moisture conditions in response to rainfall as discussed in a later section.

\section{Comparison of different observation operators}

Table 1 summarizes the results of the different upscaling methods explained in the methodology section. Pearson's linear correlation coefficient (R), root mean square error (RMSE) and mean bias error (MBE) are used to evaluate the performances of the five different observation operators. They are defined as follows:

$$
\begin{aligned}
& \text { RMSE }=\sqrt{\frac{\sum_{i=1}^{n}\left(\widehat{\theta}_{m, i}-\theta_{m, i}\right)^{2}}{n}} \\
& \mathrm{MBE}=\sum_{i=1}^{n} \frac{\left(\widehat{\theta}_{m, i}-\theta_{m, i}\right)}{n} \\
& \mathrm{R}=\frac{\sum_{i=1}^{n}\left(\widehat{\theta}_{m, i}-\overline{\widehat{\theta}}_{\mathrm{m}}\right)\left(\theta_{m, i}-\bar{\theta}_{m}\right)}{\sqrt{\sum_{i=1}^{n}\left(\widehat{\theta}_{m, i}-\overline{\hat{\theta}}_{\mathrm{m}}\right)^{2} \sum_{i=1}^{n}\left(\theta_{m, i}-\bar{\theta}_{m}\right)^{2}}}
\end{aligned}
$$

Where $\hat{\theta}_{m, i}$ and $\theta_{m, i}$ are estimated field averages (from different observation operators) and true (assumed) field averages from spatial measurements for time step $i$, respectively, and $\overline{\hat{\theta}}_{\mathrm{m}}$ and $\bar{\theta}_{m}$ are the temporal means of them.

The CDF matching method shows the best results for all datasets: correlation coefficients are close to $0.99, \mathrm{RMSE}$ is improved more than an order of magnitude from the original dataset (P) and bias is successfully reduced to zero. Successful application of the CDF matching method was also presented in the previous study by De Lannoy et al. (2007).

MRD-ST method using the most temporally stable points provides the second best results 
(Table 1). Heathman et al. (2012) determined that locations \#17 and \#21 are the most temporally stable sites (having smallest standard deviations of MRD) for AS1 and AS2, respectively for the same 2009 dataset. They also showed that the observations from those temporally stable sites can be successfully converted to field averages using a constant offset (Equation 5) resulting in a coefficient of determination $\left(\mathrm{R}^{2}\right)$ greater than 0.95 . For the 2010 datasets, locations \#8 and \#19 were found to be the most temporally stable for $5 \mathrm{~cm}$ and $20 \mathrm{~cm}$ depth, respectively at AS1, and locations \#30 and \#21 for $5 \mathrm{~cm}$ and $20 \mathrm{~cm}$ depth, respectively at AS2 (Figure 2). This MRD-ST method improved overall error statistics, especially $\mathrm{R}$ for $5 \mathrm{~cm}$ depth measurements. However, $\mathrm{R}$ for $20 \mathrm{~cm}$ data at AS2 for 2010 decreased to 0.887 even when compared to the original permanent sensor measurements $(=0.944)$. This coincides with the smaller slope (deviating from the 1:1 line) of the linear trend line and low $\mathrm{R}^{2}(=0.7857)$ of linear regressions between the actual field averages and the estimated field averages using the constant offset value, compared to the other datasets in Figure 7. AS2-20cm in 2010, has a very high MRD (18\%) compared to other datasets. Due to the multiplicative relationship of MRD-ST method, amplitude of the estimated field average becomes smaller with the positive MRD (18\%). The degree of decrease in amplitude is much larger for wet soil moisture conditions. Thus, there exists greater error at higher soil moisture values as shown in Figure 7(d). This fact shows that the MRD-ST method does not work well for data having a high MRD.

The disadvantage of the MRD-ST method is that it does not remove bias completely. Although this method improves R and RMSE values, with values comparable to the CDF matching method, some datasets $(5 \mathrm{~cm}$ in 2009 and 5cm in 2010 for AS1) in Table 1 still have non-zero MBE. In addition, Figure 8 shows that this method is not successful in predicting several peak soil moisture conditions (e.g. August 11, September 7 and 8 for AS1 and July 23 for AS2).

MRD-P method using the permanent sensors measurements resulted in little improvement compared to the original data $(\mathrm{P})$ in Table 1; RMSE is improved slightly, and MBE is decreased but still remains non-zero for all datasets. These results might be expected based on the previous temporal stability studies because permanent sensor measurements had high standard deviations of MRD for both AS1 and AS2 (Figure 2) especially in 2009. Standard deviations of MRD of the permanent sensor measurements at $5 \mathrm{~cm}$ depth at AS1 is $21.9 \%$ and $6.2 \%$ compared to $3.9 \%$ and $4.4 \%$ of the temporally stable locations in 2009 and 2010, respectively. Standard deviations of MRD of the permanent sensor measurements at $5 \mathrm{~cm}$ depth at AS2 is $15 \%$ and $10.2 \%$ compared to 
$3.6 \%$ and $2.6 \%$ of the temporally stable locations in 2009 and 2010, respectively. Results of the

2 MRD-P method in Table 1 show that the dataset with a higher standard deviation for MRD (e.g. AS1 and AS2 in 2009 and AS2-5 $\mathrm{cm}$ in 2010) show less improvement compared to the other dataset with smaller standard deviations. Therefore, Equation 7 which adjusts the point measurements to

5 field averages using the constant offset is not suitable for temporally unstable point measurements, such as the data from the permanent sensors in the present study.

The AMD method using absolute mean difference is not very successful in upscaling the point measurements to the field averages, except in removing bias as intended (Table 1). The LR method using simple linear relationships produces better results than either AMD or MRD-P, but much less successful results than either the CDF matching or the MRD-ST. Due to relatively stable soil moisture conditions at the $20 \mathrm{~cm}$ depth compared to the surface layer, upscaling results for the LR method with $20 \mathrm{~cm}$ measurements data are quite good; the LR method produces less RMSE than MRD-ST for the AS2 data in 2010 in Table 1.

Figure 8 compares the results of different observation operators graphically for the 2009 datasets. Results for the CDF matching and the MRD-ST methods show that upscaling permanent sensor measurements to the field averages was successful, whereas the other three methods fail to do so.

Table 2 illustrates coefficients of the different observation operators for each dataset. Some of the coefficients from different datasets have similar magnitudes but others have very different magnitudes indicating little possibility of their transferability between datasets.

\subsection{Spatial and temporal transferability of observation operators from CDF matching}

Six datasets obtained from different years (2009 and 2010), sites (AS1 and AS2) and depths $(5 \mathrm{~cm}$ and $20 \mathrm{~cm})$ allow us to test whether the aforementioned observation operators are transferable in time and space. The results in Table 1 are used as reference to evaluate the spatial and temporal transferability of different observation operators illustrated in Table 3 .

\section{Temporal transferability for two different years (2009 vs. 2010)}

The first two sections in Table 3 are results of applying the observation operators from another time period in order to test temporal transferability of the observation operators. For example, the observation operator obtained from 2009 data was used to upscale the permanent sensor measurements of the year 2010. As expected from the very different shapes of CDF curves for the 
1 data from 2009 and 2010 in Figure 5, the error statistics are not satisfactory, indicating unsuccessful temporal transferability of the observation operators. While correlations are improved with the MRD-ST and CDF matching methods compared to the statistics of the original data $(\mathrm{P})$ in Table 1, error terms are in general increased using observation operators from another time period. There are slight improvements in terms of RMSE or MBE with some methods (e.g. MRD-ST and LR with AS1 data), but the improvements are not consistent for all datasets. Unlike the results of CDF matching method, the MRD-ST method is temporally transferable only for AS1 data producing less errors and higher correlation coefficients than the results of $\mathrm{P}$. This is because of the offset values in the similar range (0.061 in 2009 and 0.102 in 2010) for AS1 data, and this simple relationship with fewer parameters produces more robust results than the CDF matching method having a higher number of parameters. However, the MRD-ST is not temporally transferable for AS2 data of which offset values have different signs.

There seems to be two major possible reasons for this unsuccessful temporal transferability: different rainfall distribution or characteristics, and different crop type in 2009 and 2010. Although the total amount of rainfall at AS1 was greater in $2009(225 \mathrm{~mm})$ than in $2010(130 \mathrm{~mm})$ for the same period (July 15 to September 20), the year of 2010 had more evenly-distributed rainfall events (Figure 9), whereas the year of 2009 had a long dry period before heavy rainfall occurred in the middle of August. In addition, initial soil moisture conditions in 2010 were very wet due to the heavy rains a few days before installing temporary sensors. Thus, the field averages of surface soil moisture $(5 \mathrm{~cm})$ in 2010 were wetter than those in 2009 (Figure 5). Different crop type (soybean in 2009 and corn in 2010 at both AS1 and AS2) is also an important factor in considering the failure of temporal transferability. However, in this study, it is difficult to isolate the effect of crop type on transferability due to the difference in the major forcing variable, rainfall in those two years.

Besides these two main factors, rotational tillage practices (only for AS2) and local heterogeneity at the location where the permanent sensors are installed may affect the soil moisture variation between 2009 and 2010. The permanent sensor measurements did not show consistent relationship with the field averages in 2009 and 2010. In 2010, both permanent sensors at AS1 and AS2 underestimated the field average soil moisture conditions consistently, whereas the permanent sensor at AS2 consistently overestimated the field averages in 2009 (Figure 5). Since the permanent sensors are located near the outlet and boundary of the watersheds, they seem to be 
more sensitive to dry or wet conditions. Whereas AS1 is in no-tillage every year, the AS2 field was tilled in 2010 before planting corn. Less residue cover due to tillage operations in 2010 at AS2 could result in drier surface soil moisture conditions, however, any effects of tillage seem to be overshadowed by yearly rainfall differences since AS2 had wetter soil conditions in 2010 than in 52009.

\section{Spatial transferability at two different locations (AS1 vs. AS2)}

Successful spatial transferability of the observation operators with the 2009 data would not be expected due to significant differences in the shape of CDF curves (Figure 5 (a) and (b)) and the observation operators (Figure 6) of AS1 and AS2. However, with the 2010 data, the curves are more similar, which are more conducive for spatial transferability.

Error statistics in the third and fourth section of Table 3 are results of the application of observation operators from another site in order to examine spatial transferability of observation operators between AS1 and AS2. The results show that the observation operators only from MRDST and CDF matching method are overall spatially transferable; both R and RMSE are improved compared to the original permanent sensor measurements ( $\mathrm{P}$ in Table 1) except for the $20 \mathrm{~cm}$ data for AS2 in 2010. Therefore, for those two upscaling methods it may be possible to use an alternative observation operator from a nearby site under similar climate, soil and crop conditions, like AS1 and AS2, when an observation operator for a site is not available. However, as mentioned earlier, the MRD-ST method uses information from the most temporally stable location, not the permanent sensor and therefore is limited to temporary measurements during short term period. In spite of possible spatial transferability of MRD-ST and CDF methods with improved R and RMSE in Table 3, however, careful application of the observation operators from another site should be required because they may highly overestimate wet conditions or underestimate dry conditions.

Compared to 2009 data, the 2010 data have more consistent trends of CDFs between AS1 and AS2. Therefore, the results of spatial transferability in 2010 show greater improvement, especially for AS1; even simple observation operators such as LR and AMD reduce RMSE. This is because the permanent sensor at AS1 highly underestimated the field averages in 2010 (Figure 5 (c) and (e)), and therefore any simple adjustments could reduce the bias in the permanent sensor measurements.

Even though temporal transferability was not shown to be successful as mentioned above, 
spatial transferability of observation operators may be possible. Rainfall characteristics appear to be the dominating factor in determining the success of transferability of observation operators, even when considering that AS1 and AS2 are close enough in proximity to assume they are under the same climate conditions. Different tillage practices and slightly different soil properties between AS1 and AS2 seem to be less critical than the differences in rainfall in the present study; AS2 has slightly more clay content than AS1 (Heathman et al., 2012), with AS2 being tilled in the spring and AS1 remaining in no-till in 2010. Considering that soil moisture was measured only during the summer period and several months after tillage, this study does not have sufficient data to determine the effects of tillage on the observation operator and therefore further research on this topic is required. Again, the effect of different crop types is difficult to determine because AS1 and AS2 have the same crop every year.

\section{Spatial transferability at two different depths $(5 \mathrm{~cm}$ vs. $20 \mathrm{~cm})$}

The last two sections in Table 3 show the results of applying the observation operators from different soil depths at the same sites. Since the permanent sensors at both AS1 and AS2 consistently underestimated the field averages at both $5 \mathrm{~cm}$ and $20 \mathrm{~cm}$ depths in 2010 (Figure 5), the observation operators are expected to be transferable vertically. Table 3 shows that observation operators from another depth produce better error statistics for almost all cases than the original permanent sensor measurements ( $\mathrm{P}$ in Table 1). Since the permanent sensor at AS1 highly underestimated the field averages (Figure 5), even simple observation operator from another depth can improve the upscaling results. However, data at AS2 did not have significant differences between the permanent sensor measurements and field averages. Therefore, AS2 data show less improvement than AS1. Overall, MRD-ST and CDF matching methods perform the best for vertical transferability. Again, the MRD-ST method may not be a practical solution to answer our initial question, 'How to use the point soil moisture measurements by the permanent sensors to obtain field representative soil moisture conditions?'

Compared to the temporal and spatial transferability tests mentioned above, vertical transferability test has fewer factors that may affect the results. Soil properties at $5 \mathrm{~cm}$ and $20 \mathrm{~cm}$ depth are very similar for both AS1 and AS2 (Heathman et al., 2012). In general, when only one observation operator from soil moisture measurements is available, either for the $5 \mathrm{~cm}$ or $20 \mathrm{~cm}$ depth, it can be used to upscale the point measurements from the other depth to field averages as 
an alternative.

\subsection{Estimation of standard deviation}

\section{Relationship between field averages and spatial variability of soil moisture}

Identifying the relationship between field average and spatial variability of soil moisture has been an important issue because of the need to: 1) determine optimal numbers of sampling points in order to estimate field averages within certain specified error limits, 2) infer soil moisture variability within a footprint, given remotely sensed soil moisture for an area, and 3) assess the varying accuracy of the remotely sensed soil moisture (Famiglietti et al., 1999; Brocca et al., 2007). As Brocca et al. (2007) summarized, previous studies showed contrasting results on the relationship between mean and variance of soil moisture conditions. Some of these studies showed increasing variances with increasing means of soil moisture while others showed inversely proportional relationships between them. However, a number of previous studies showed strong negative relationships between mean soil moisture and the coefficient of variation $(C V=\sigma(\theta) / \bar{\theta})$ (Charpentier and Groffman, 1992; Famiglietti et al., 1999; Jacobs et al., 2004; Brocca et al., 2007; Famiglietti et al., 2008; Choi and Jacobs, 2011; Brocca et al., 2012). This is because the relationship between field average and the variability of soil moisture becomes more evident when the standard deviation $(\sigma)$ is scaled by the mean soil moisture $(\bar{\theta})$.

In the present study, the field averages and the standard deviations (STDEV) of surface $(5 \mathrm{~cm})$ soil moisture measurements do not show any distinct relationship at either AS1 or AS2 (Figure 10(a) and (c)). Note that graphs for AS2 are not shown, but overall trends between mean soil moisture and STDEV (or CV) are similar to those of AS1 in Figure 10. This seems to be because surface soil moisture variation is very dynamic due to the effect of evaporation. Recently, Famiglietti et al. (2008) showed that the relationship between mean soil moisture and STDEV at small scales $(2.5 \mathrm{~m} \sim 800 \mathrm{~m})$ was not very well-defined for the SGP99 data, while a more clearly defined convex upward trend in the relationship was present in the large scale 5-cm soil moisture data (800m and 50km) from the SMEX 02 and SMEX 03 campaigns. Brocca et al. (2012) showed a similar convex upward relationship between mean and STDEV at the local scale, as well as the catchment scale for in situ soil moisture data collected at the $0-15 \mathrm{~cm}$ depth interval. Therefore, the relationship between mean soil moisture and STDEV can vary depending on the experimental scale and observational depth. 
Another difference in the data from this study compared to previous studies is that more frequent measurements (every 30 minutes) were used in the present study compared to daily measurements. When the soil is fully saturated after a significant rainfall event, the STDEV decreases considerably and then increases as the soil dries. The minimum STDEV was found on August 17 when the heaviest rainfall occurred (Figure 3). Therefore, variations of the STDEV of soil moisture highly depend on rainfall intensity (characteristics) and antecedent soil moisture conditions. A moderate amount of rainfall (e.g. July 25) or rainfall with dry antecedent soil moisture conditions (e.g. August 11), increases the STDEV, whereas heavy rainfall (e.g. August 17) or rainfall with wet antecedent soil moisture conditions (e.g. September 7) results in decreased STDEV. Unlike the relationship for the surface soil moisture, the relationships between mean soil moisture and STDEV are more evident for the $20 \mathrm{~cm}$ depth measurements due to relatively homogeneous and more stable conditions in the deeper soil layers (Figure 10 (e)).

When relative variability, measured by $\mathrm{CV}$, is applied, more distinguishable relationships between the mean and variability of soil moisture are revealed as shown in Figure 7(b), (d) and (f). The negative relationships between the mean and CV of soil moisture were successfully described using an exponential fit, $C V=a \cdot \exp (b \cdot \bar{\theta})$ in previous studies (Jacobs et al., 2004; Brocca et al., 2007; Choi and Jacobs, 2011). The results of exponential fit with data from the present study are shown in Table 4. Once these relationships (coefficients $a$ and $b$ ) and field averages $(\bar{\theta})$ are known, the $\operatorname{STDEV}(\sigma)$ of the soil moisture can be estimated $(\hat{\sigma}=C V \cdot \bar{\theta})$. The last three columns of Table 4 show error statistics of the estimated STDEV from the exponential equations. Since surface $(5 \mathrm{~cm})$ soil moisture measurements have relatively low $\mathrm{R}^{2}$ with the exponential curve fitting, the resulting error statistics are not satisfactory, especially having very low correlation coefficients (R). Although several previous studies adopted the exponential relationship between the mean and CV to determine optimal numbers of sampling points with a certain specified error (Jacobs et al., 2004; Brocca et al., 2007; Brocca et al., 2010a), our present study did not achieve successful prediction of STDEV due to the weak relationship between the mean and the CV. In the following section, results of an alternative method to estimate STDEV using the CDF matching method are introduced.

Figure 11 shows observed (red line) STDEV and estimated (gray line) STDEV by the CDF 
matching method for six different datasets. The STDEVs of the soil moisture varied dynamically with time due to rainfall and evapotranspiration. In 2009, AS1 and AS2 had STDEVs in similar ranges, whereas in 2010 the variations of STDEVs at the two sites were very different from each other. In 2010, AS2 had higher STDEVs and more dynamic variation of STDEVs than those of AS1 for surface $(5 \mathrm{~cm})$ soil moisture. Even though AS2 has slightly more clay content than AS1, surface soil moisture at AS2 varied more dynamically than AS1. This is most likely due to the tillage management and thus, having less residue cover in field AS2 (tilled surface) in 2010 may cause more of a response at the soil surface due to rainfall and evaporation. The lowest STDEVs with $5 \mathrm{~cm}$ data at AS2 in Figure 11(d) correspond to major rainfall events. Deeper soil layers in AS1 and AS2 responded in the opposite way compared to the surface soil layer in 2010. STDEVs of the $20 \mathrm{~cm}$ measurements at AS1 changed more dynamically. For example, STDEVs were reduced abruptly with major rainfall events on August 11 and September 2. However, STDEVs of the $20 \mathrm{~cm}$ measurements at AS2 rarely changed with time. This may possibly be due to higher clay content at this depth in AS2.

The CDF matching method successfully estimated the dynamic variations of STDEVs for all datasets as Figure 11 and Table 5 show. Correlation coefficients between the observed and 17 predicted STDEVs are higher than 0.9, except for the 5cm measurements at AS1 in 2009 (Table 5). Comparisons of error statistics in Table 4 and Table 5 demonstrate that STDEV prediction by CDF matching is much more successful compared to applying the exponential relationship between the mean and STDEV of soil moisture. The advantage of this STDEV prediction method using CDF matching is that it can be applied to any soil moisture fields, whether or not soil moisture variability has any specific trend or relationship with the field averages. This also shows that the CDF matching method can be used to estimate STDEVs of the field soil moisture as well as field averages using point measurements. Since the third order polynomial fit was adopted consistently in this study, there were high errors with some data, especially with minimum or maximum values. For example, the STDEVs are highly overestimated or underestimated on July 271 in Figure 11(d), (e) and (f). In this study, actual 30-minute measurements were used for analysis. 28 Therefore, changes of STDEVs with rainfall events are clearly noticeable. If daily average 29 measurements are used, the dynamic variations would be much less apparent. 


\section{Conclusions}

The primary purpose of this study is to estimate field representative characteristics of soil moisture (field averages and STDEV) using single point measurements. First, for upscaling the point soil moisture measurements to field averages, some limitations of the temporal stability analysis that has been used widely for this purpose are discussed. Next, alternative upscaling methods, mainly focusing on the CDF matching method, are investigated to test whether they offer means to overcome the limitations of the temporal stability analysis. The difference between the present study and that of De Lannoy et al. (2007) is that temporal and spatial transferability of different observation operators are evaluated for practical applications of the upscaling approaches. Second, spatial variabilities of soil moisture are estimated from point soil moisture measurements using the CDF matching method.

The results show that the CDF matching method is the best observation operator to estimate the field average soil moisture from single point measurements by permanent sensor. The mean relative difference (MRD) method using the most temporally stable point measurements can also produce satisfactory results, after the CDF matching method. However, the MRD method is not applicable in reality because the permanent sensors cannot be installed "in-field" due to agricultural operations and because the locations of the most temporally stable points are not consistent in time or for different depths. Evaluation of the additional three observation operators, based on simple linear relationships, absolute mean differences, and mean relative differences using the permanent sensor measurements, proved to be unsuccessful in this study.

By comparing datasets from different time periods, areas and soil layers, temporal and spatial transferabilities of the observation operators are examined. Overall the observation operators only from MRD-ST and CDF matching methods are found to be spatially and vertically transferable, but not temporally transferable. Rainfall characteristics and crop type are most likely to be the most significant factors influencing the transferabilities in this study. Other factors such as differences in soil properties, tillage practices and topography may be important as well, but in this study, they appear to be less influential in the transferability of the observation operators than differences due to the rainfall and crop type. Further detailed studies are required to better understand the effect of these factors. 
The unsuccessful temporal transferability of the observation operators in this study has important implications for data assimilation studies and long term validation of remote sensing data. Especially in many data assimilation studies, where the same CDF parameters obtained from a certain time period when both modeled and observed data are available were used for hydrological predictions for another period (e.g. Scipal et al. (2008), Brocca et al. (2010b) and Dharssi et al. (2011)). Drusch et al. (2005) also addressed this temporal transferability issue of the observation operator and concluded that temporally changing observation operators are required. Although analysis of the present study is limited to small agricultural fields ( $\sim 2 \mathrm{ha})$ and short term observations, further studies for larger areas and long term observations are necessary for more operational applications. A recent study by Heathman et al. (in press) provides analysis of soil moisture variations from point to field to watershed scale in an effort to address several of the issues discussed in this paper. Besides field averages, standard deviations of soil moisture within the fields are also estimated using single point measurements from the edge-of-field permanent sensors. Dynamic variations of standard deviations are successfully predicted through the similar CDF matching method. This approach, which estimates time-series soil moisture variance using point measurements, has potential for various practical applications such as soil moisture data assimilation, land surface modeling, assessing the accuracy of remote sensed soil moisture and establishing optimal in situ soil moisture networks.

The CDF matching approach of this study allows estimations of both field averages and STDEV from point measurements at the permanent soil moisture sensor locations. This approach is expected to contribute to better utilization of in situ soil moisture networks which are established for the calibration and validation of remotely sensed soil moisture products but often times consist of a limited number of permanent soil moisture sensors. The study areas of present study are part of the current monitoring network in UCCW that are planned to be used for the validation of SMAP soil moisture products at various resolutions $(3,9,36 \mathrm{~km})$ in the near future. Therefore, findings of this study provide significant insight as to designing better validation schemes for SMAP soil moisture products.

The SMAP Cal/Val Plan contains various aspects of validation approaches from using the in situ networks to model-based validations (Jackson et al., 2010a). The temporal stability analysis is one of the tentative methods for validation of SMAP products using in situ soil moisture networks. However, the temporal stability analysis has several limitations in determining 
1 spatially representative soil moisture values as discussed in Section 2. The CDF matching

2 method has been shown to be a successful transforming (upscaling) method in this study and

3 should be considered for the validation of remotely sensed soil moisture, supplementing other

4 validation methods such as the triple collocation method (Miralles et al., 2010).

5 Overall, this study examines the capability of different upscaling methods at the agricultural

6 field scale for soil moisture measured in limited time periods (summer periods for two different

7 years). Despite the significant findings of this study, several science questions remain

8 unanswered and are the subject for future research: 1) How can we expand the upscaling

9 approach to watershed scale for the validation of SMAP products at various resolutions? What

10 other factors should be considered for watershed level upscaling?, 2) Are the observation

11 operators spatially transferable to areas beyond the field scale?, 3) How does the length of the

12 temporal sampling affect the observation operators? How long of an observation period is

13 required to obtain temporally transferable observation operators if they exist? and 4) Can we

14 separate the effect of crop types on the soil moisture variability from the effect of rainfall

15 characteristics? These are only some of the questions that may be answered with increased

16 availability of observational data in the near future. 


\section{Reference}

Abrahamson, D.A. et al., 2006. Evaluation of the RZWQM for simulating tile drainage and leached nitrate in the Georgia piedmont. Agronomy Journal, 98(3): 644-654.

Anagnostou, E.N., Negri, A.J. and Adler, R.F., 1999. Statistical adjustment of satellite microwave monthly rainfall estimates over Amazonia. Journal of Applied Meteorology, 38(11): 1590-1598.

Atlas, D., Rosenfeld, D. and Wolff, D.B., 1990. Climatologically tuned reflectivity-rain relations and links to areatime integrals. Journal of Applied Meteorology, 29(11): 1120-1135.

Brocca, L., Melone, F., Moramarco, T. and Morbidelli, R., 2010a. Spatial-temporal variability of soil moisture and its estimation across scales. Water Resources Research, 46.

Brocca, L. et al., 2010b. Improving runoff prediction through the assimilation of the ASCAT soil moisture product. Hydrology and Earth System Sciences, 14(10): 1881-1893.

Brocca, L., Morbidelli, R., Melone, F. and Moramarco, T., 2007. Soil moisture spatial variability in experimental areas of central Italy. Journal of Hydrology, 333(2-4): 356-373.

Brocca, L., Tullo, T., Melone, F., Moramarco, T. and Morbidelli, R., 2012. Catchment scale soil moisture spatialtemporal variability. Journal of Hydrology, 422??23(0): 63-75.

Charpentier, M.A. and Groffman, P.M., 1992. Soil moisture variability within remote sensing pixels. Journal of Geophysical Research-Atmospheres, 97(D17): 18987-18995.

Choi, M. and Jacobs, J.M., 2008. Temporal variability corrections for Advanced Microwave Scanning Radiometer E (AMSR-E) surface soil moisture: Case study in Little River Region, Georgia, U. S. Sensors, 8(4): 2617-2627.

Choi, M. and Jacobs, J.M., 2011. Spatial soil moisture scaling structure during Soil Moisture Experiment 2005. Hydrological Processes, 25(6): 926-932.

Cosh, M.H., Jackson, T.J., Bindlish, R. and Prueger, J.H., 2004. Watershed scale temporal and spatial stability of soil moisture and its role in validating satellite estimates. Remote Sensing of Environment, 92(4): 427-435.

Cosh, M.H., Jackson, T.J., Starks, P. and Heathman, G., 2006. Temporal stability of surface soil moisture in the Little Washita River watershed and its applications in satellite soil moisture product validation. Journal of Hydrology, 323(1-4): 168-177.

Crow, W.T., Ryu, D. and Famiglietti, J.S., 2005. Upscaling of field-scale soil moisture measurements using distributed land surface modeling. Advances in Water Resources, 28(1): 1-14.

Crow, W.T. and van den Berg, M.J., 2010. An improved approach for estimating observation and model error parameters in soil moisture data assimilation. Water Resources Research, 46.

De Lannoy, G.J.M., Houser, P.R., Verhoest, N.E.C., Pauwels, V.R.N. and Gish, T.J., 2007. Upscaling of point soil moisture measurements to field averages at the OPE3 test site. Journal of Hydrology, 343(1-2): 1-11.

Dharssi, I., Bovis, K.J., Macpherson, B. and Jones, C.P., 2011. Operational assimilation of ASCAT surface soil wetness at the Met Office. Hydrology and Earth System Sciences, 15(8): 2729-2746.

Drusch, M., Wood, E.F. and Gao, H., 2005. Observation operators for the direct assimilation of TRMM microwave imager retrieved soil moisture. Geophysical Research Letters, 32(15).

Famiglietti, J.S. et al., 1999. Ground-based investigation of soil moisture variability within remote sensing footprints during the Southern Great Plains 1997 (SGP97) Hydrology Experiment. Water Resources Research, 35(6): 1839-1851.

Famiglietti, J.S., Ryu, D.R., Berg, A.A., Rodell, M. and Jackson, T.J., 2008. Field observations of soil moisture variability across scales. Water Resources Research, 44(1).

Flanagan, D., Huang, C.H., Pappas, E., Smith, D. and Heathman, G., 2008. Assessing conservation effects on water quality in the St. Joseph River Watershed, Proceedings of the AgroEnviron 2008 (Sixth International Symposium AgroEnviron), Antalya, Turkey, pp. 12.

Grayson, R.B. and Western, A.W., 1998. Towards areal estimation of soil water content from point measurements: time and space stability of mean response. Journal of Hydrology, 207(1-2): 68-82.

Han, E., Merwade, V. and Heathman, G.C., 2011. Application of data assimilation with the root zone water quality model for soil moisture profile estimation in the upper Cedar Creek, Indiana. Hydrological Processes: doi: 10.1002/hyp.8292.

Heathman, G., Cosh, M.H., Merwade, V. and Han, E., in press. Multi-scale temporal stability analysis of surface and subsurface soil moisture within the Upper Cedar Creek Watershed, Indiana. Catena.

Heathman, G.C. et al., 2012. Field scale spatiotemporal analysis of surface soil moisture for evaluating point-scale in situ networks. Geoderma, 170(0): 195-205.

Heathman, G.C., Larose, M., Cosh, M.H. and Bindlish, R., 2009. Surface and profile soil moisture spatio-temporal 
analysis during an excessive rainfall period in the Southern Great Plains, USA. CATENA, 78(2): 159-169.

Heathman, G.C., Starks, P.J., Ahuja, L.R. and Jackson, T.J., 2003. Assimilation of surface soil moisture to estimate profile soil water content. Journal of Hydrology, 279: 1-17.

Jackson, T., Kimball, J., Colliander, A. and Njoku, E.G., 2010a. Soil Moisture Active and Passive (SMAP) Mission - Science Calibration and Validation Plan, SMAP Science Document, No:014. SMAP Science Document, No:014.

Jackson, T.J. et al., 2010b. Validation of Advanced Microwave Scanning Radiometer Soil Moisture Products. IEEE Transactions on Geoscience and Remote Sensing, 48(12): 4256-4272.

Jacobs, J.M., Mohanty, B.P., Hsu, E.-C. and Miller, D., 2004. SMEX02: Field scale variability, time stability and similarity of soil moisture. Remote Sensing of Environment, 92(4): 436-446.

Joshi, C., Mohanty, B.P., Jacobs, J.M. and Ines, A.V.M., 2011. Spatiotemporal analyses of soil moisture from point to footprint scale in two different hydroclimatic regions. Water Resources Research, 47.

Liu, Y.Y. et al., 2011. Developing an improved soil moisture dataset by blending passive and active microwave satellite-based retrievals. Hydrology and Earth System Sciences, 15(2): 425-436.

Liu, Y.Y., van Dijk, A., de Jeu, R.A.M. and Holmes, T.R.H., 2009. An analysis of spatiotemporal variations of soil and vegetation moisture from a 29-year satellite-derived data set over mainland Australia. Water Resources Research, 45.

Loew, A. and Schlenz, F., 2011. A dynamic approach for evaluating coarse scale satellite soil moisture products. Hydrology and Earth System Sciences, 15(1): 75-90.

Martinez-Fernandez, J. and Ceballos, A., 2005. Mean soil moisture estimation using temporal stability analysis. Journal of Hydrology, 312(1-4): 28-38.

Matgen, P. et al., 2011. On the potential of METOP ASCAT-derived soil wetness indices as a new aperture for hydrological monitoring and prediction: a field evaluation over Luxembourg. Hydrological Processes: doi:10.1002/hyp.8316.

Miralles, D.G., Crow, W.T. and Cosh, M.H., 2010. Estimating Spatial Sampling Errors in Coarse-Scale Soil Moisture Estimates Derived from Point-Scale Observations. Journal of Hydrometeorology, 11(6): 1423-1429.

Mohanty, B.P. and Skaggs, T.H., 2001. Spatio-temporal evolution and time-stable characteristics of soil moisture within remote sensing footprints with varying soil, slope, and vegetation. Advances in Water Resources, 24(9-10): 1051-1067.

Reichle, R.H. and Koster, R.D., 2004. Bias reduction in short records of satellite soil moisture. Geophysical Research Letters, 31(19).

Robinson, D.A. et al., 2008. Soil moisture measurement for ecological and hydrological watershed-scale observatories: A review. Vadose Zone Journal, 7(1): 358-389.

Scipal, K., Drusch, M. and Wagner, W., 2008. Assimilation of a ERS scatterometer derived soil moisture index in the ECMWF numerical weal-her prediction system. Advances in Water Resources, 31(8): 1101-1112.

Starks, P.J., Heathman, G.C., Jackson, T.J. and Cosh, M.H., 2006. Temporal stability of soil moisture profile. Journal of Hydrology, 324(1-4): 400-411.

Vachaud, G., Desilans, A.P., Balabanis, P. and Vauclin, M., 1985. Temporal stability of spatially measured siol water probability density function. Soil Science Society of America Journal, 49(4): 822-828.

Verstraeten, W.W., Veroustraete, F. and Feyen, J., 2008. Assessment of evapotranspiration and soil moisture content across different scales of observation. Sensors, 8(1): 70-117.

Walker, J.P., Willgoose, G.R. and Kalma, J.D., 2001a. One-dimensional soil moisture profile retrieval by assimilation of near-surface measurements: A simplified soil moisture model and field application. Journal of Hydrometeorology, 2(4): 356-373.

Walker, J.P., Willgoose, G.R. and Kalma, J.D., 2001b. One-dimensional soil moisture profile retrieval by assimilation of near-surface observations: a comparison of retrieval algorithms. Advances in Water Resources, 24: 631650 .

Western, A.W., Grayson, R.B. and Bloschl, G., 2002. Scaling of soil moisture: A hydrologic perspective. Annual Review of Earth and Planetary Sciences, 30: 149-180.

Wood, A.W., Maurer, E.P., Kumar, A. and Lettenmaier, D.P., 2002. Long-range experimental hydrologic forecasting for the eastern United States. Journal of Geophysical Research-Atmospheres, 107(D20). 
(a) AS1

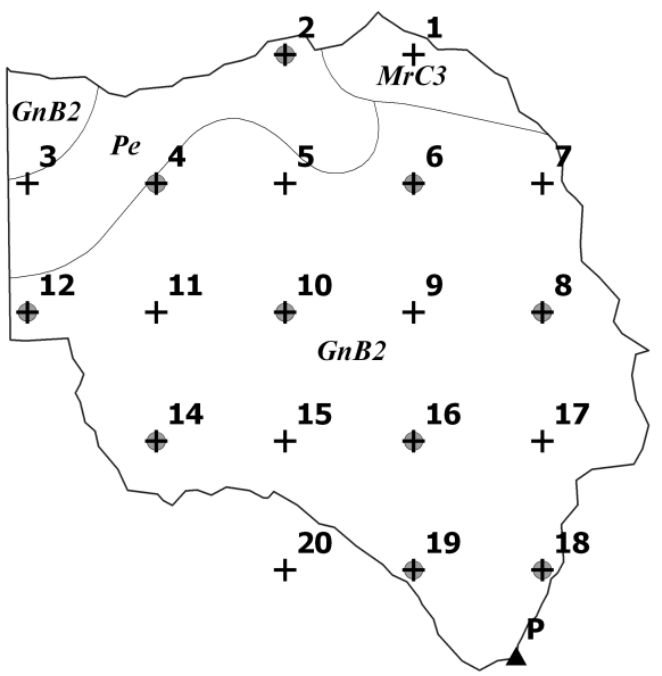

(b) AS2

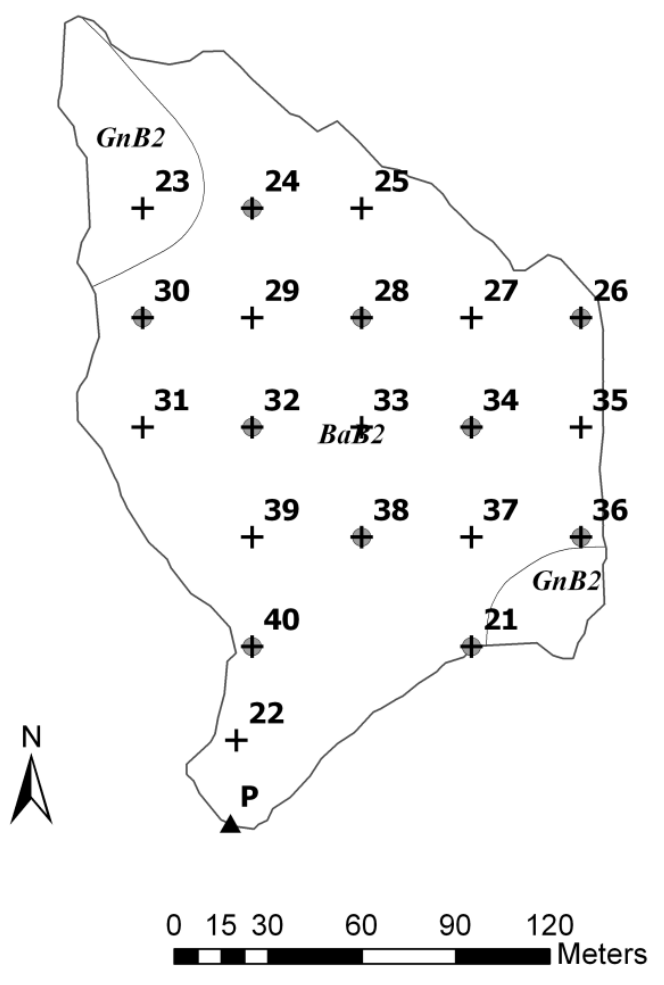

A Permanent sensor

$+2009$

- 2010

Figure 1.Study area - AS1 and AS2. 


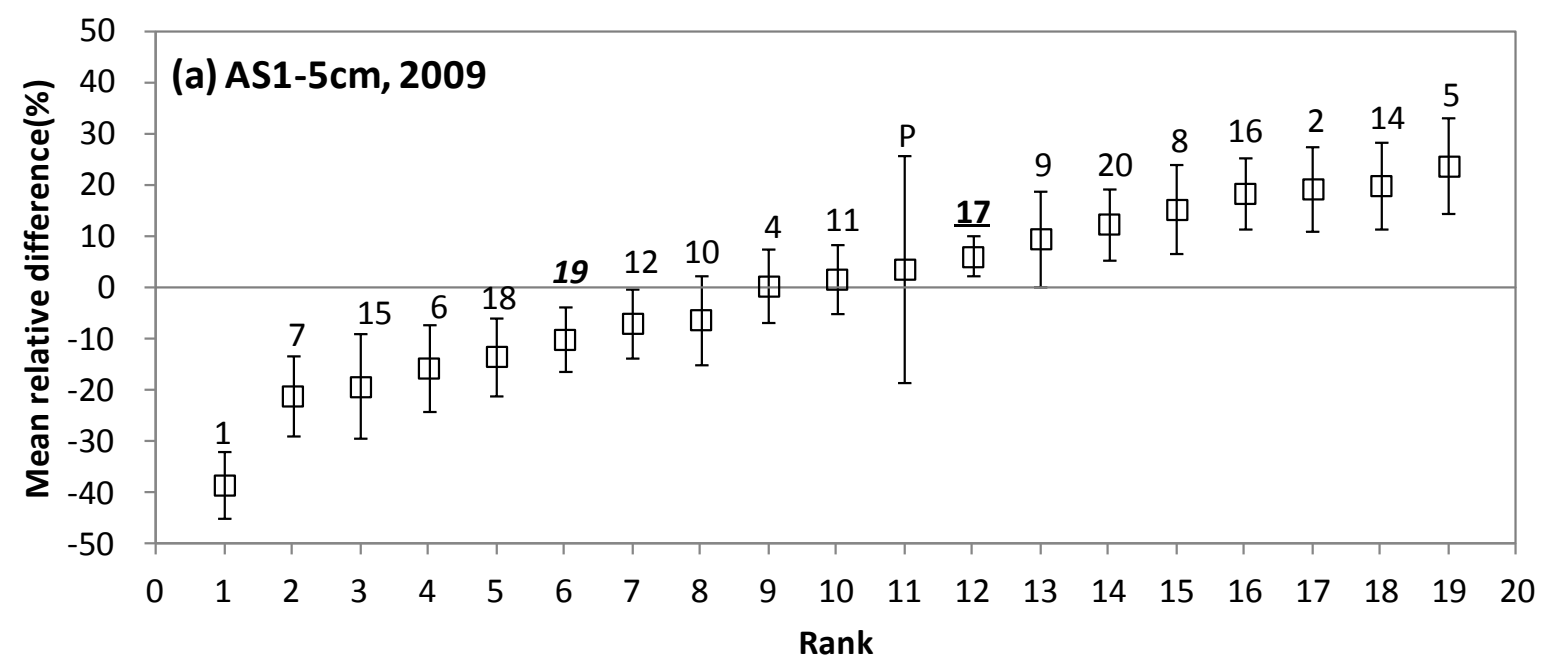

1
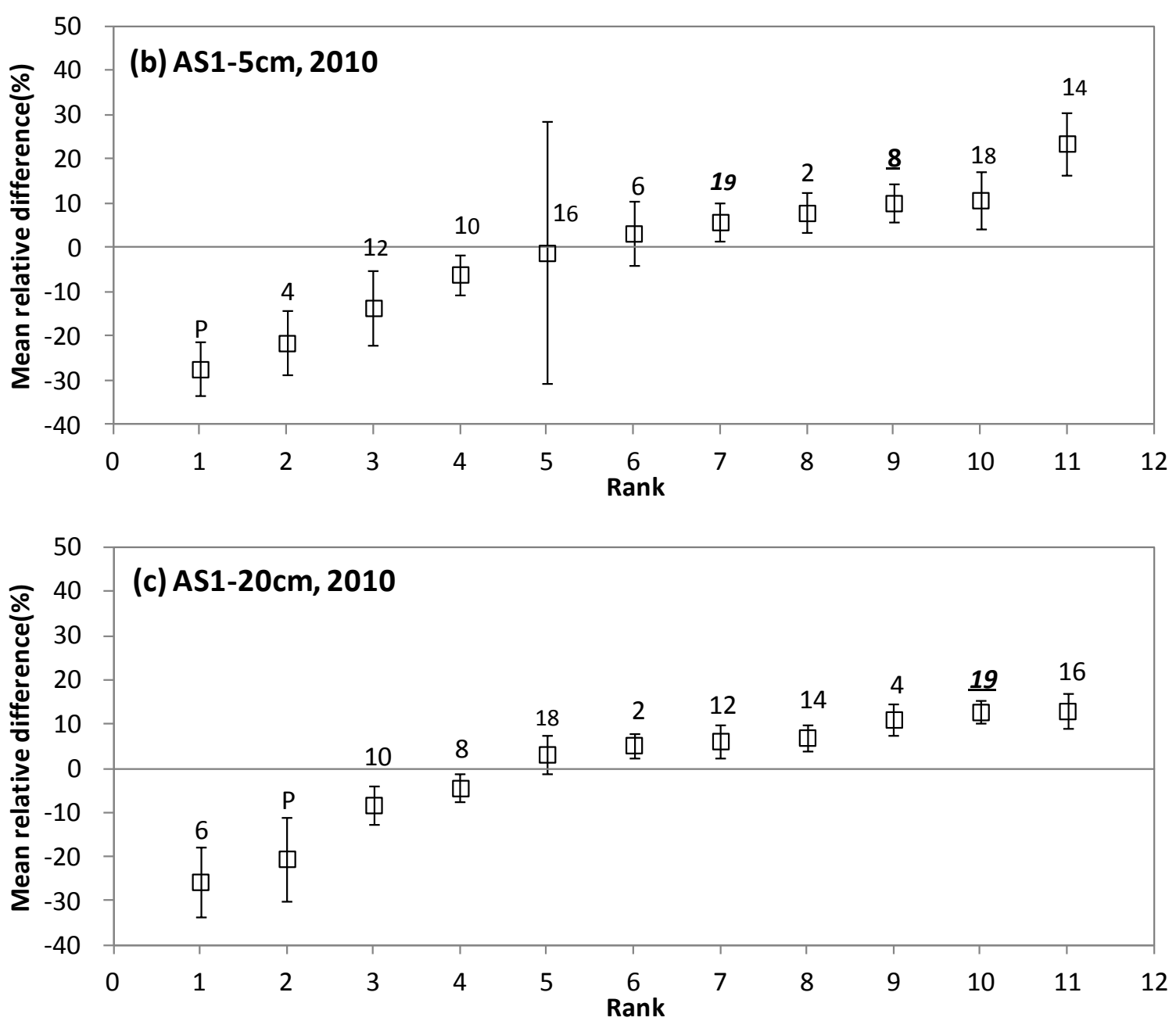


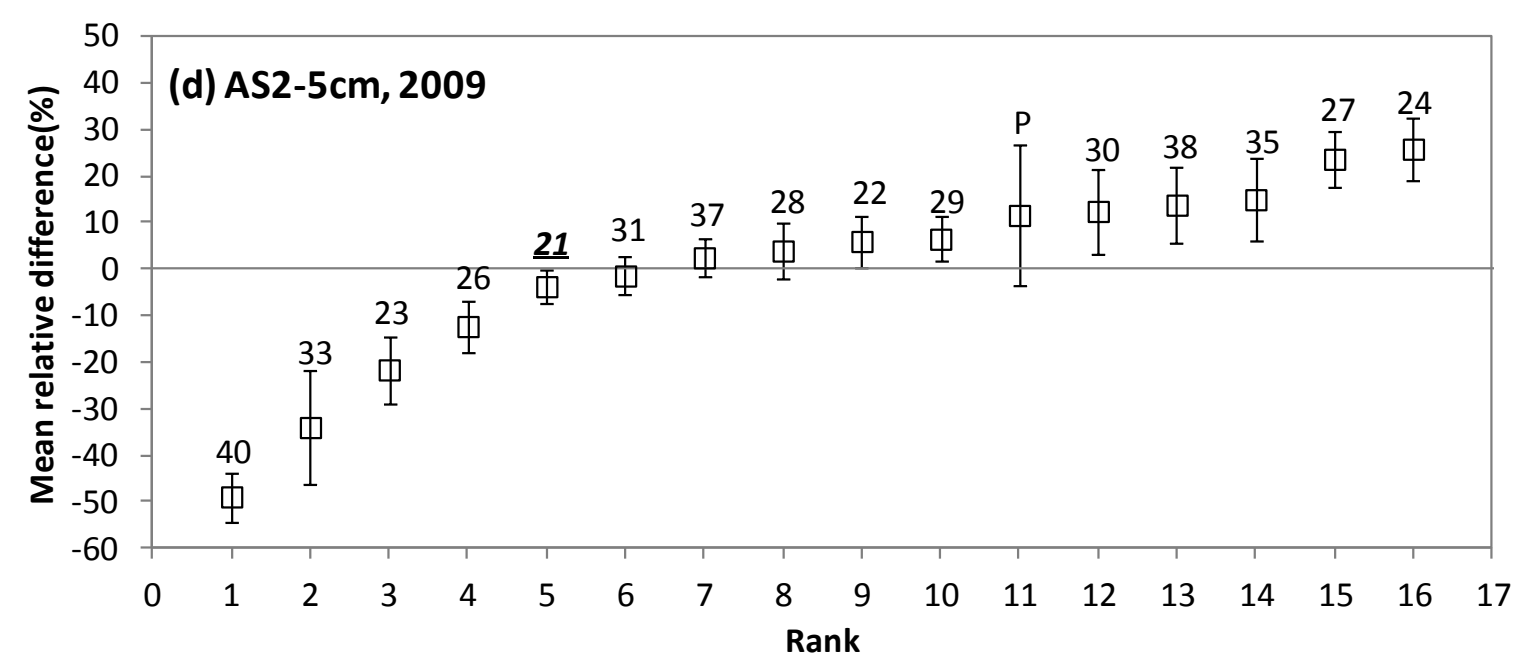

1
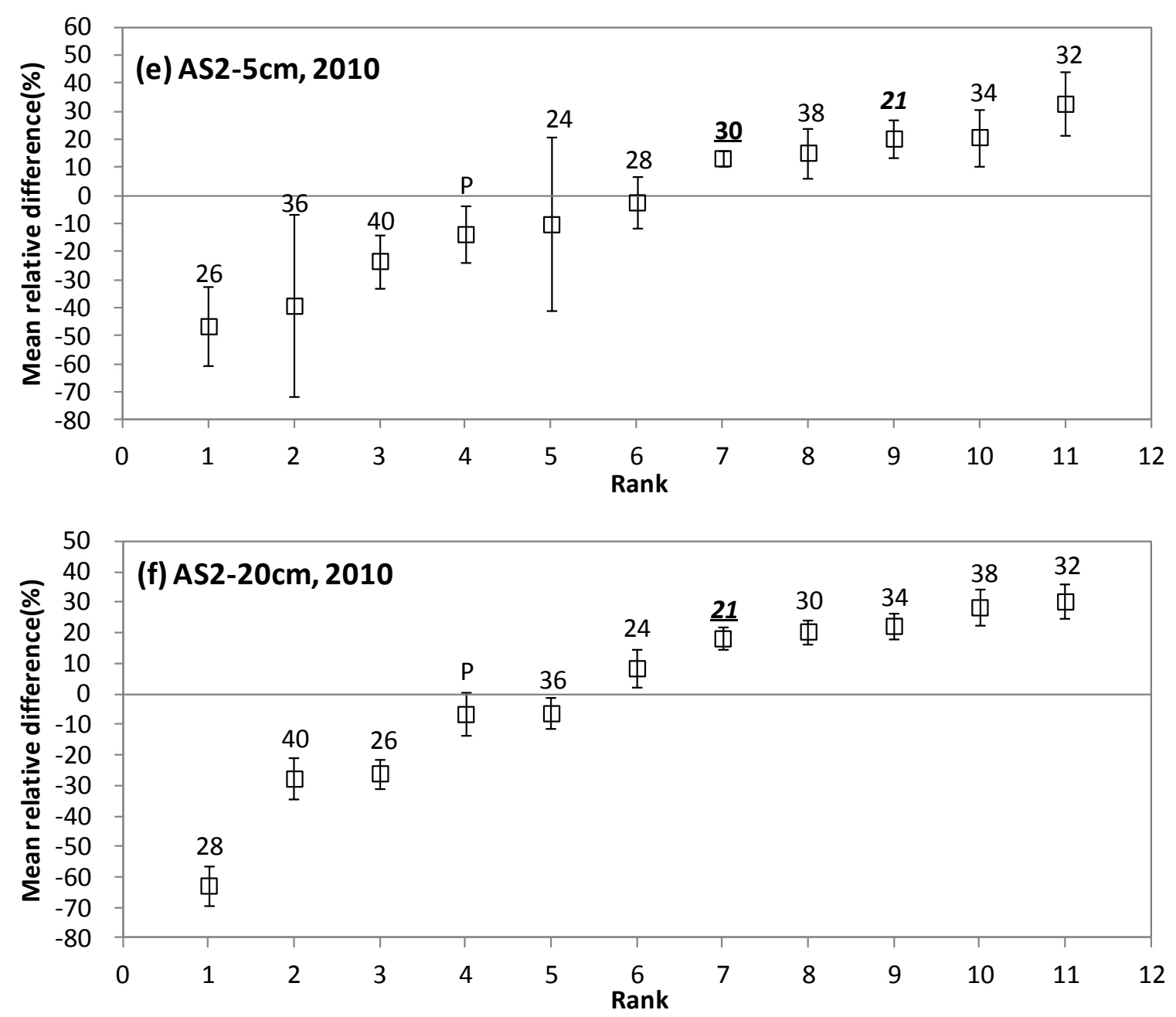

Figure 2.Ranked mean relative difference for; (a)AS1, $5 \mathrm{~cm}$ in 2009, (b)AS1, $5 \mathrm{~cm}$ in 2010, (c)AS1, 20cm in 2010, (d)AS1, 5cm in 2009, (e)AS2, 5cm in 2010, (f)AS2, 20cm in 2010. The most temporally stable locations are indicated in bold with underbar. 

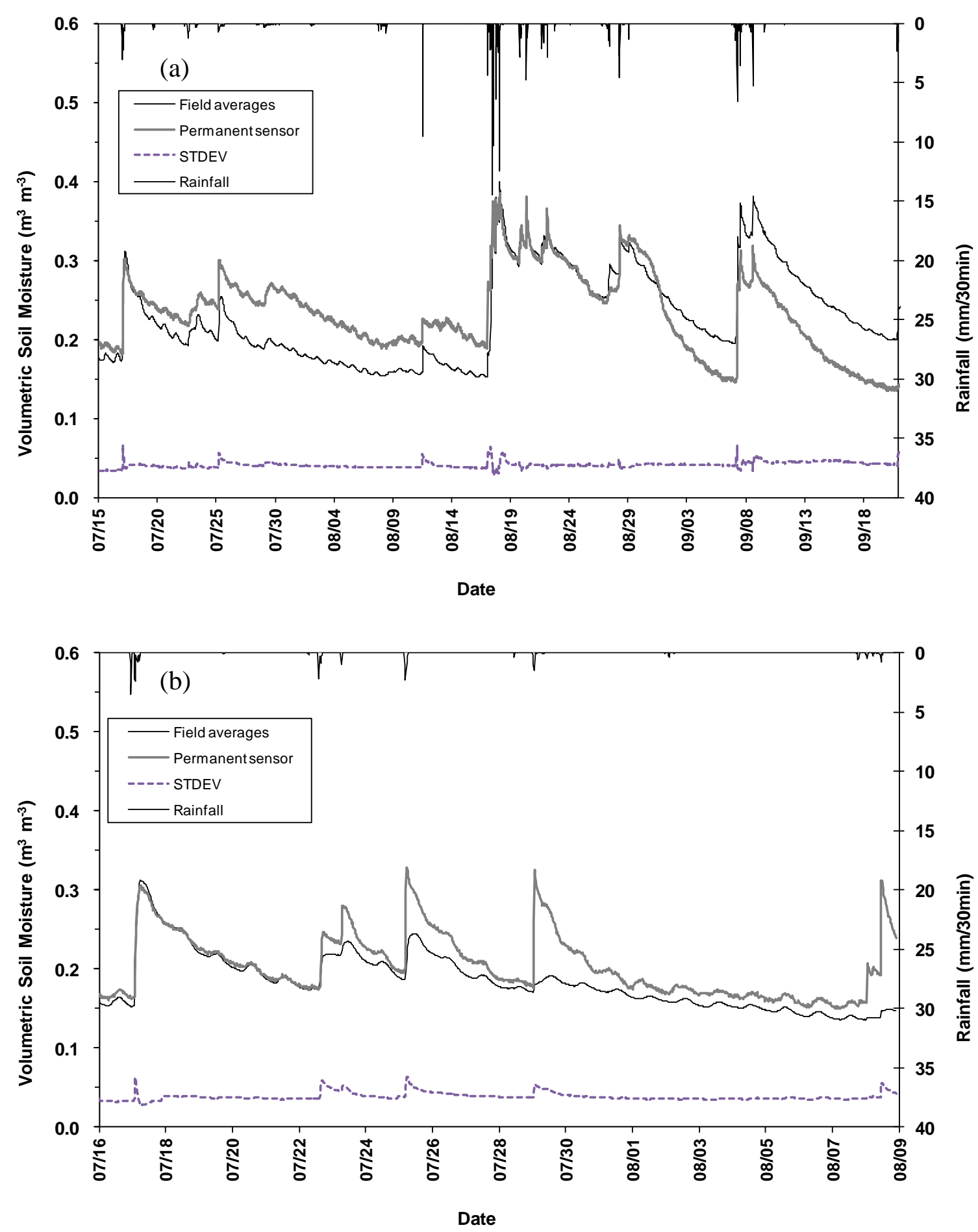

3 Figure 3. Soil moisture observations from the permanent sensor, field average and standard 4 deviation of spatial soil moisture measurements in 2009 at (a) AS1, (b) AS2. 

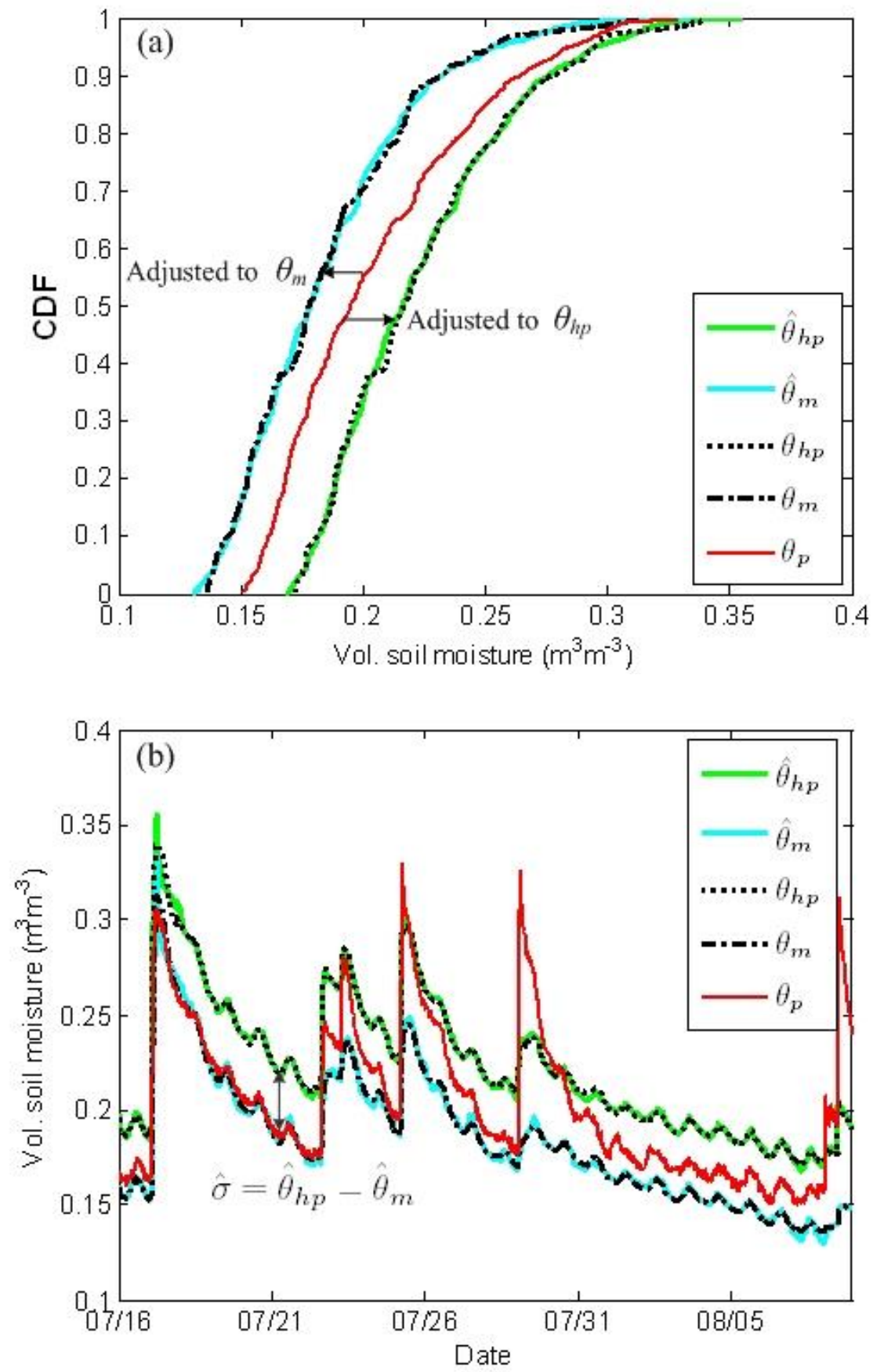

3 Figure 4. Illustration of CDF matching method to estimate field averages $\left(\widehat{\theta}_{m}\right)$ and standard 4 deviations $(\hat{\sigma})$ of soil moisture from single permanent sensor measurements $\left(\theta_{p}\right)$ at $\operatorname{AS} 2$; (a)

5 CDF matching, (b) time series of observed and estimated soil moisture. $\theta_{m}$ and $\sigma$ are true 6 (assumed) field average and standard deviation of soil moisture respectively, computed from the 
1 spatial measurements. $\theta_{h p}$ is a hypothetical soil moisture representing consistently wet

2 condition $\left(\theta_{h p}=\theta_{m}+\sigma\right)$ 3 

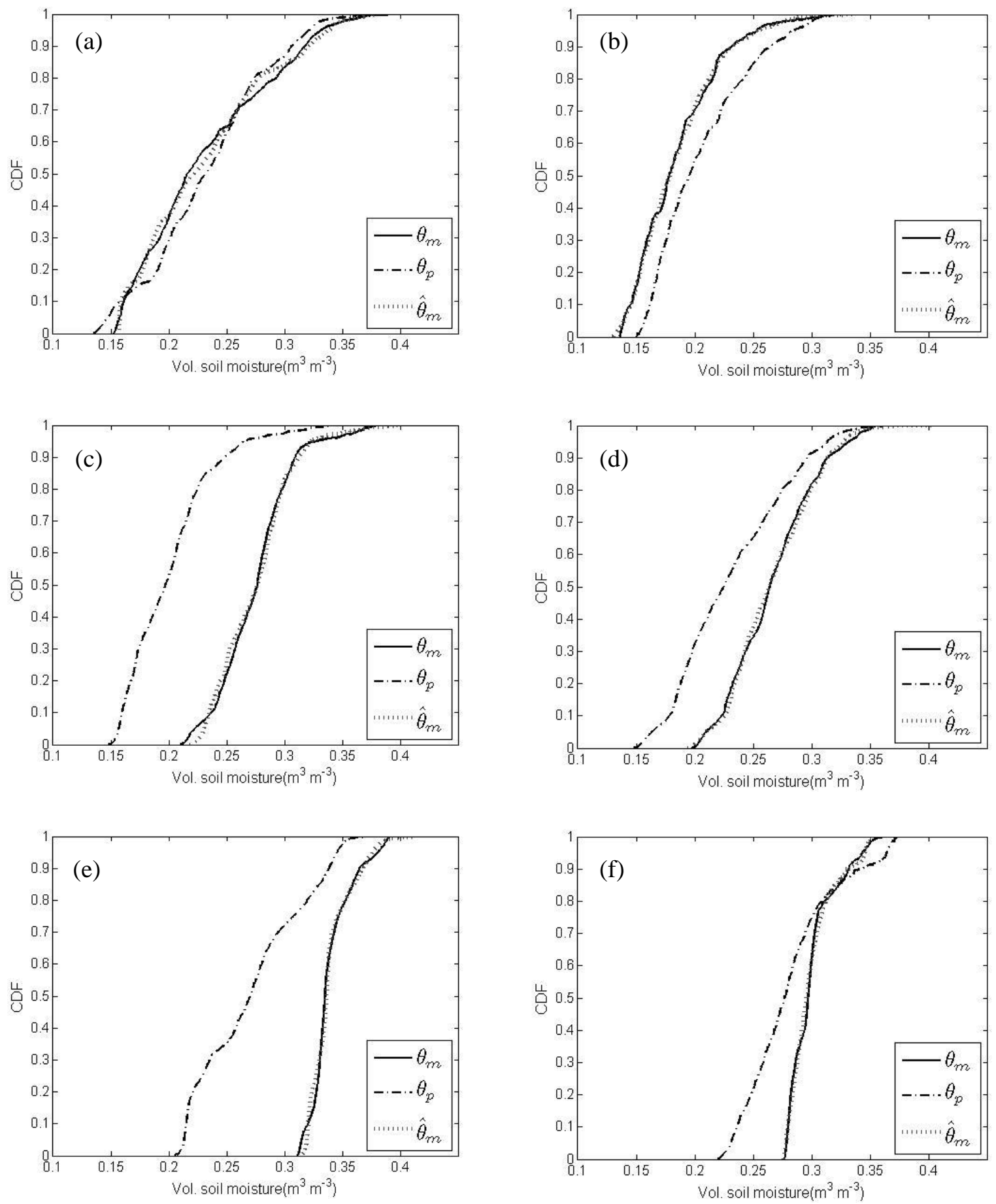

1 Figure 5. CDFs of observed and predicted soil moisture; (a) AS1, 5cm in 2009, (b)AS2, 5cm in 2 2009, (c) AS1, 5cm in 2010, (d) AS2, 5cm in 2010, (e) AS1, 20cm in 2010, (f) AS2, 20cm in 3 2010. $\theta_{m}, \theta_{p}$ and $\hat{\theta}_{m}$ represent field average (average of all spatial measurements), soil 4 moisture observations from permanent sensor, and predicted field average from $\theta_{p}$ (upscaled 5 by CDF matching), respectively. 

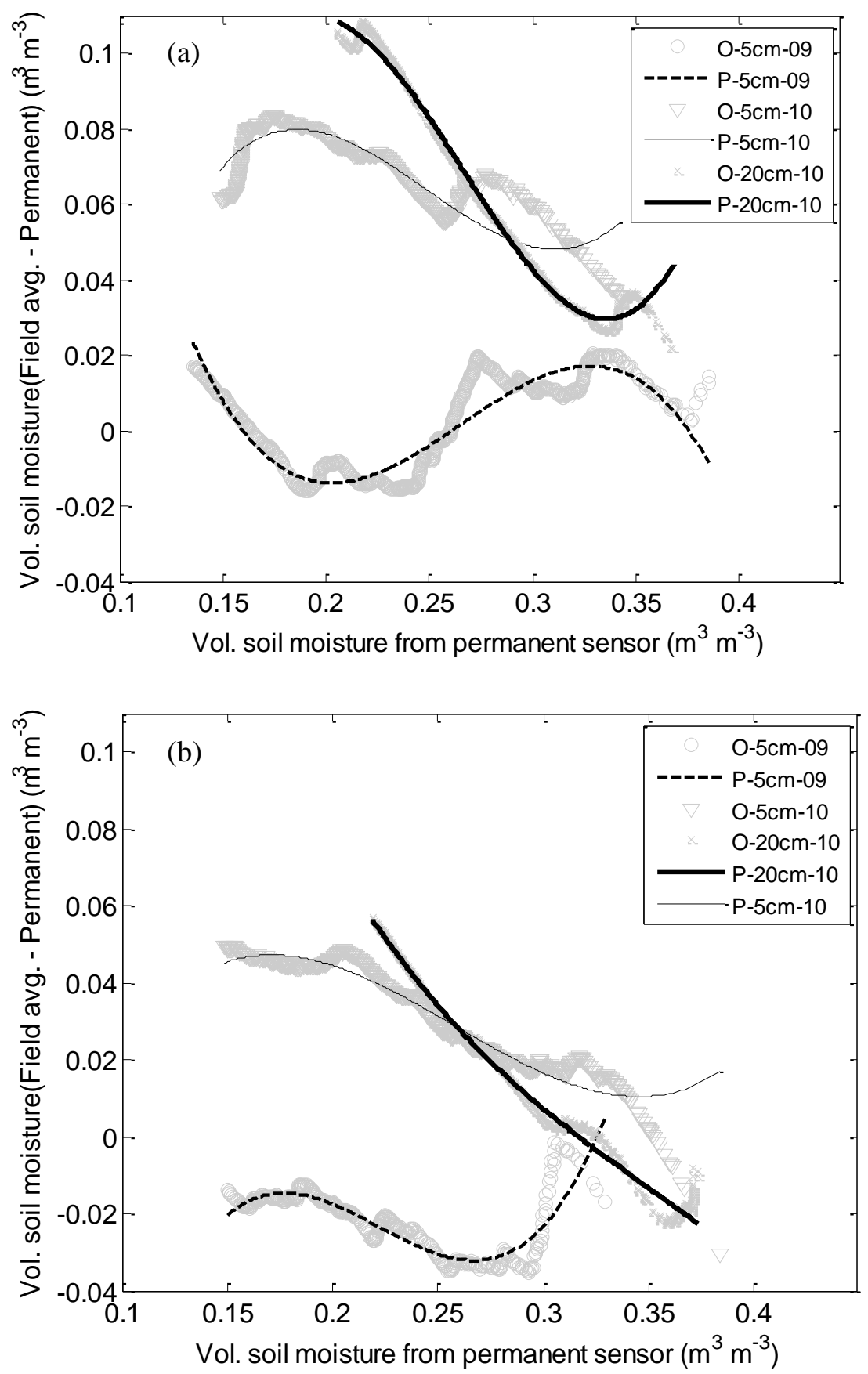

2 

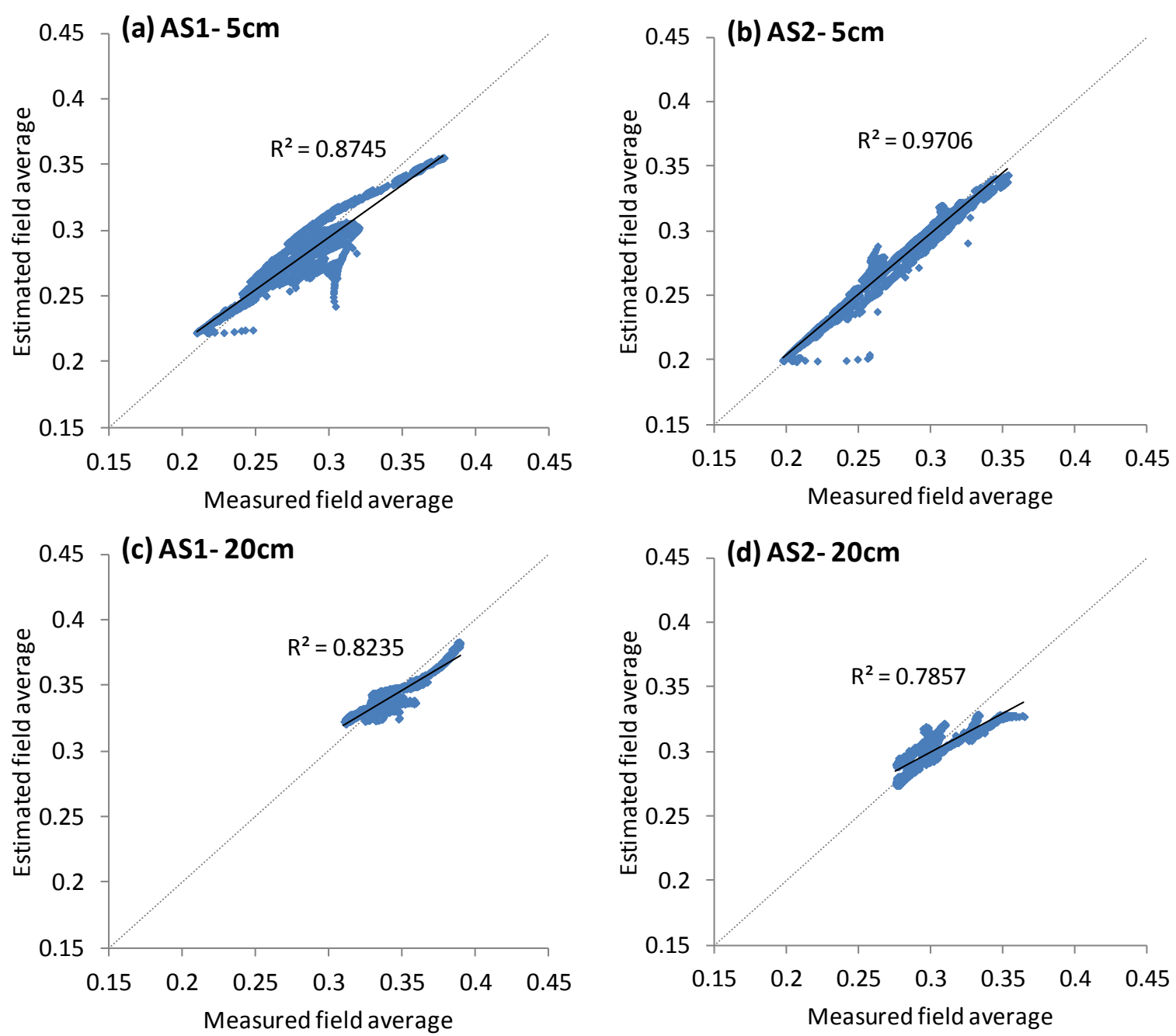

1 Figure 7. Linear regression of observed field averages and estimated average using an offset 2 (Equation 5) for soil moisture measurements in 2010 at $5 \mathrm{~cm}(\mathrm{a}$ and b) and $20 \mathrm{~cm}$ (c and d) for 3 fields AS1 and AS2, respectively. 

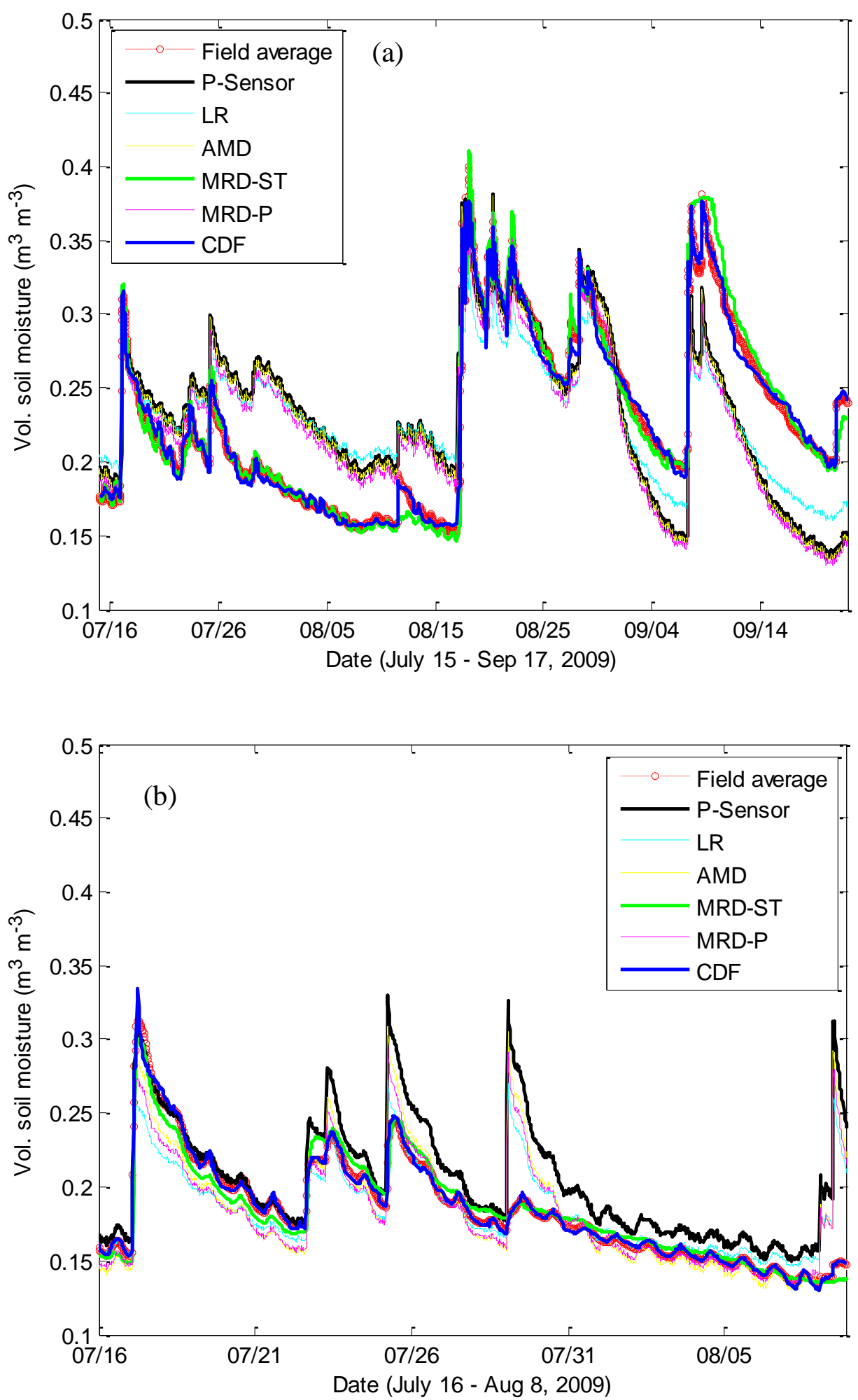

Figure 8. Time series of soil moisture for permanent sensor data, field average and the transformed permanent sensor data (a) AS1 (b) AS2. 


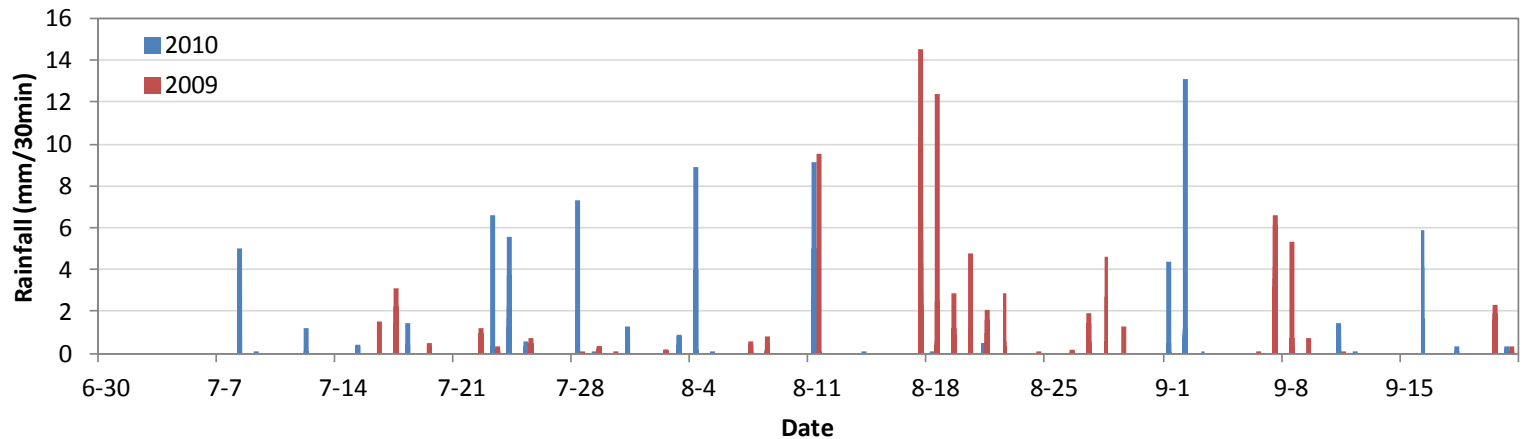

2

3

Figure 9. 30minute Rainfall comparison in 2009 and 2010. 

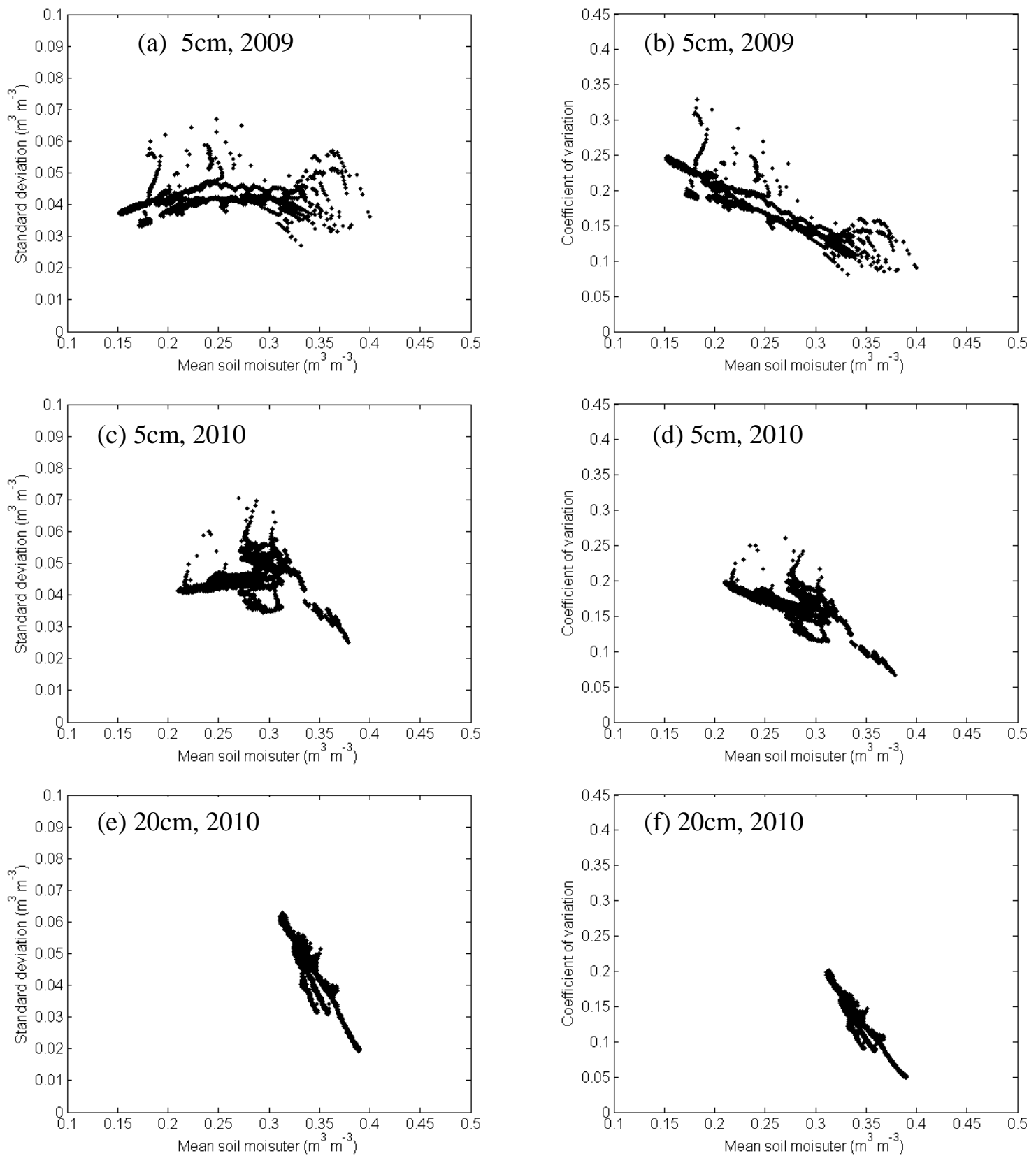

Figure 10. Relationship between mean soil moisture and standard deviation (a, c, and e) and between mean soil moisture and coefficient of variation (b, d, and f) at AS1. 

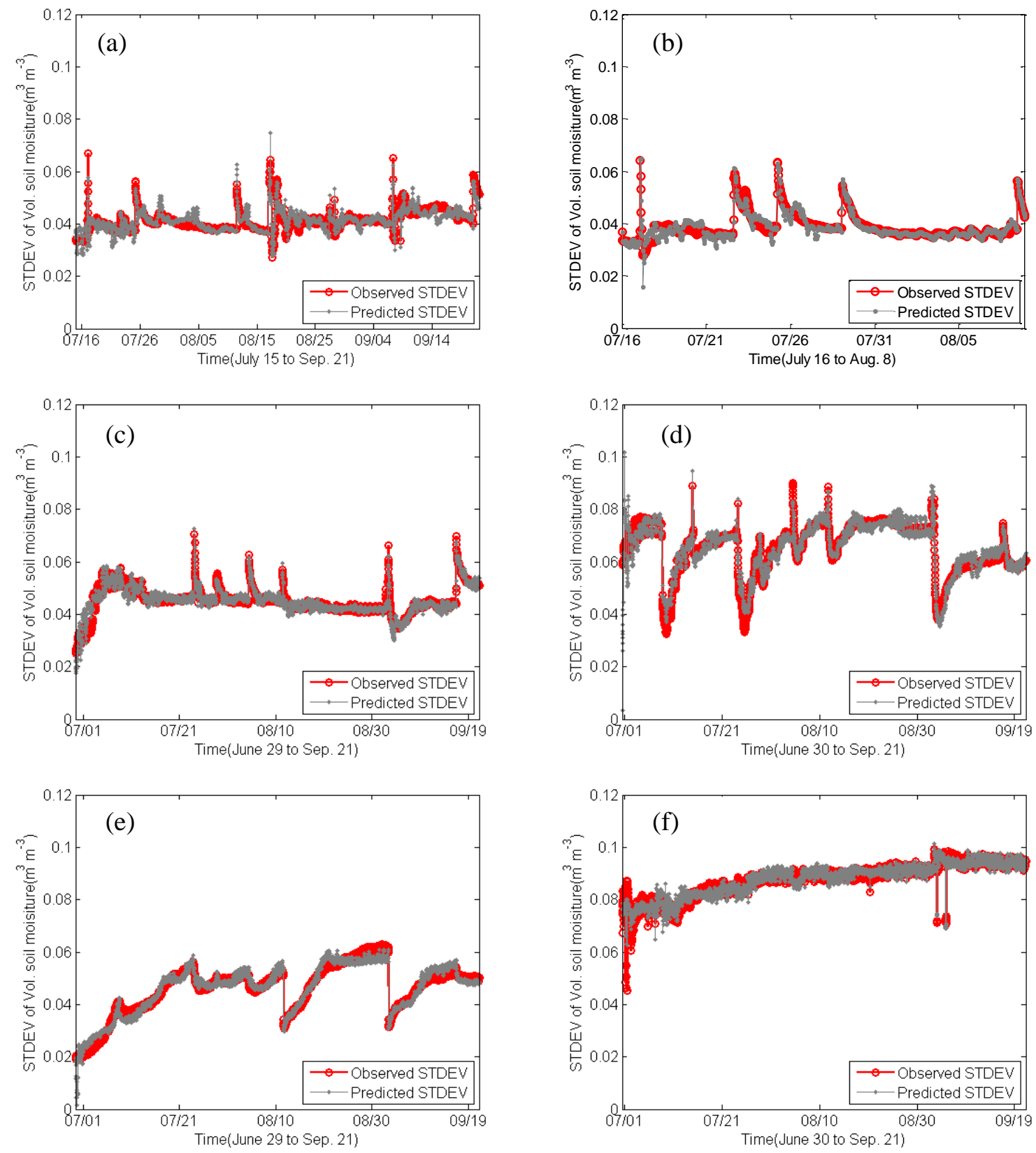

Figure 11. Observed and predicted standard deviations of the soil moisture (a) AS1, $5 \mathrm{~cm}$ in 2009, (b)AS2, 5cm in 2009, (c) AS1, 5cm in 2010, (d) AS2, 5cm in 2010, (e)AS1, 20cm in 2010, (f)AS2, 20cm in 2010 . 
1 Table 1. Performance comparison of different upscaling methods.

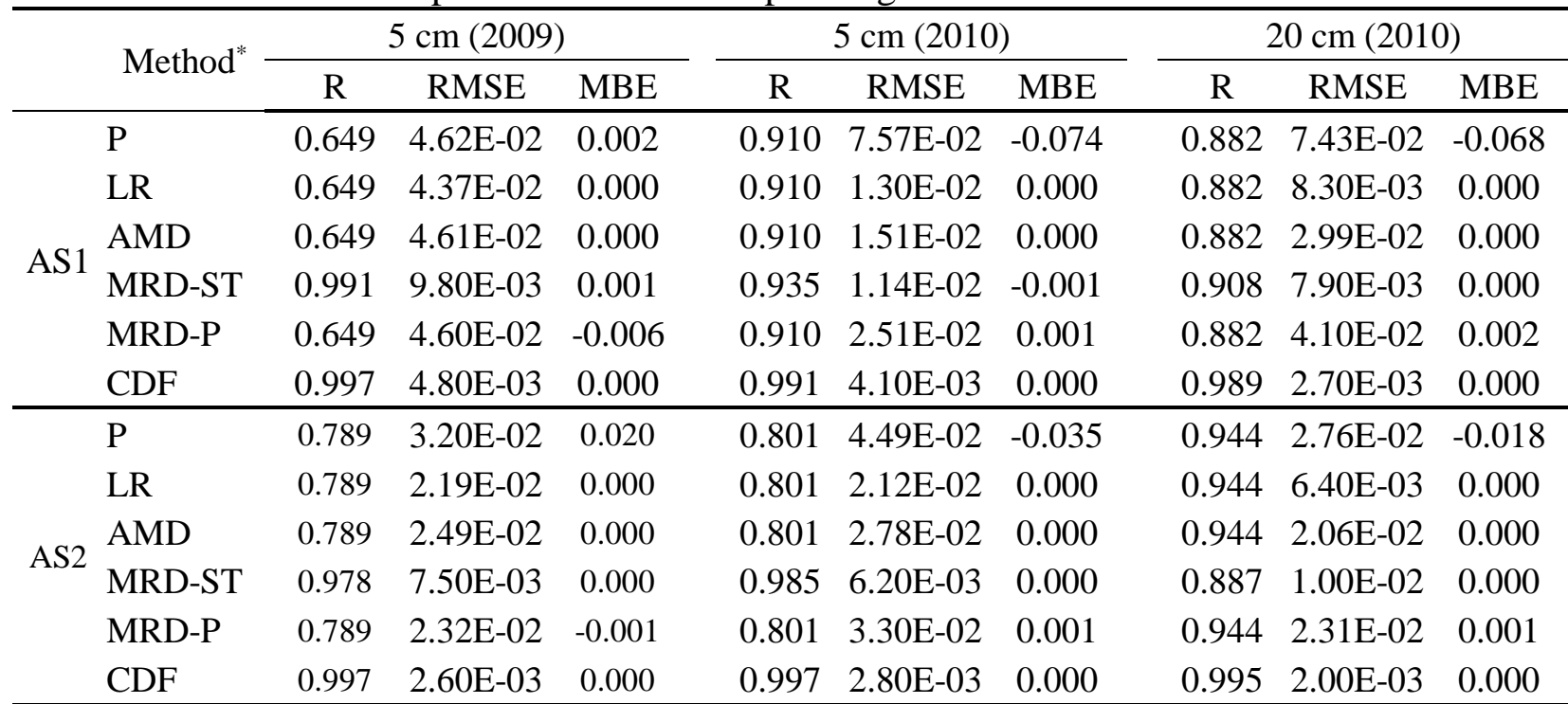

* P: original data from permanent sensor, LR: linear relationship, AMD: absolute mean difference, MRD-ST: mean relative difference from the most temporally stable site,

MRD-P: mean relative difference from the permanent sensor, CDF: CDF matching method. 
1 Table 2. Coefficients of transforming equations for upscaling from the permanent sensor 2 measurements to field averages.

\begin{tabular}{|c|c|c|c|c|c|c|c|}
\hline \multirow{2}{*}{ Method $^{*}$} & \multirow{2}{*}{ coefficients } & \multicolumn{2}{|c|}{$5 \mathrm{~cm}(2009)$} & \multicolumn{2}{|c|}{$5 \mathrm{~cm}(2010)$} & \multicolumn{2}{|c|}{$20 \mathrm{~cm}(2010)$} \\
\hline & & $\mathrm{AS} 1$ & AS2 & AS1 & AS2 & AS1 & AS2 \\
\hline \multirow{2}{*}{$\begin{array}{l}\text { LR } \\
\text { (Equation 4) }\end{array}$} & $b_{0}$ & 0.064 & 0.040 & 0.117 & 0.125 & 0.244 & 0.164 \\
\hline & $b_{1}$ & 0.718 & 0.706 & 0.787 & 0.613 & 0.351 & 0.483 \\
\hline $\begin{array}{l}\text { AMD } \\
\text { (Equation 8) }\end{array}$ & $\bar{\delta}_{a, p}$ & 0.002 & 0.020 & -0.074 & -0.035 & -0.068 & -0.018 \\
\hline $\begin{array}{l}\text { MRD-ST } \\
\text { (Equation 5) }\end{array}$ & $\bar{\delta}_{j}$ & $\begin{array}{c}0.061 \\
(\# 17)^{* *}\end{array}$ & $\begin{array}{l}-0.037 \\
(\# 21)^{* *} \\
\end{array}$ & $\begin{array}{l}0.102 \\
(\# 8)^{* *}\end{array}$ & $\begin{array}{c}0.134 \\
(\# 30)^{* *} \\
\end{array}$ & $\begin{array}{c}0.128 \\
(\# 19)^{* *}\end{array}$ & $\begin{array}{l}0.183 \\
(\# 21)^{* *}\end{array}$ \\
\hline $\begin{array}{l}\text { MRD-P } \\
\text { (Equation 7) }\end{array}$ & $\bar{\delta}_{p}$ & 0.0367 & 0.1164 & -0.274 & -0.137 & -0.2041 & -0.065 \\
\hline \multirow{4}{*}{$\begin{array}{l}\text { CDF } \\
\text { (Equation 2) }\end{array}$} & $a_{0}$ & 0.494 & -0.481 & -0.342 & -0.127 & -0.774 & 0.449 \\
\hline & $a_{1}$ & -31.595 & 47.843 & 32.537 & 13.772 & 57.008 & -7.235 \\
\hline & $a_{2}$ & 25.165 & -31.842 & -24.271 & -10.665 & -45.440 & 7.727 \\
\hline & $a_{3}$ & -6.310 & 6.773 & 5.654 & 2.437 & 11.222 & -3.138 \\
\hline
\end{tabular}

$3 *$ LR: linear relationship, AMD: absolute mean difference, MRD-ST: relative mean difference from the most temporally stable site, MRD-P: relative mean difference from the permanent sensor, CDF: CDF matching method. ** Numbers in parenthesis indicate locations of the most temporally stable sensors. 
1 Table 3. Spatiotemporal transferabilities of different observation operators.

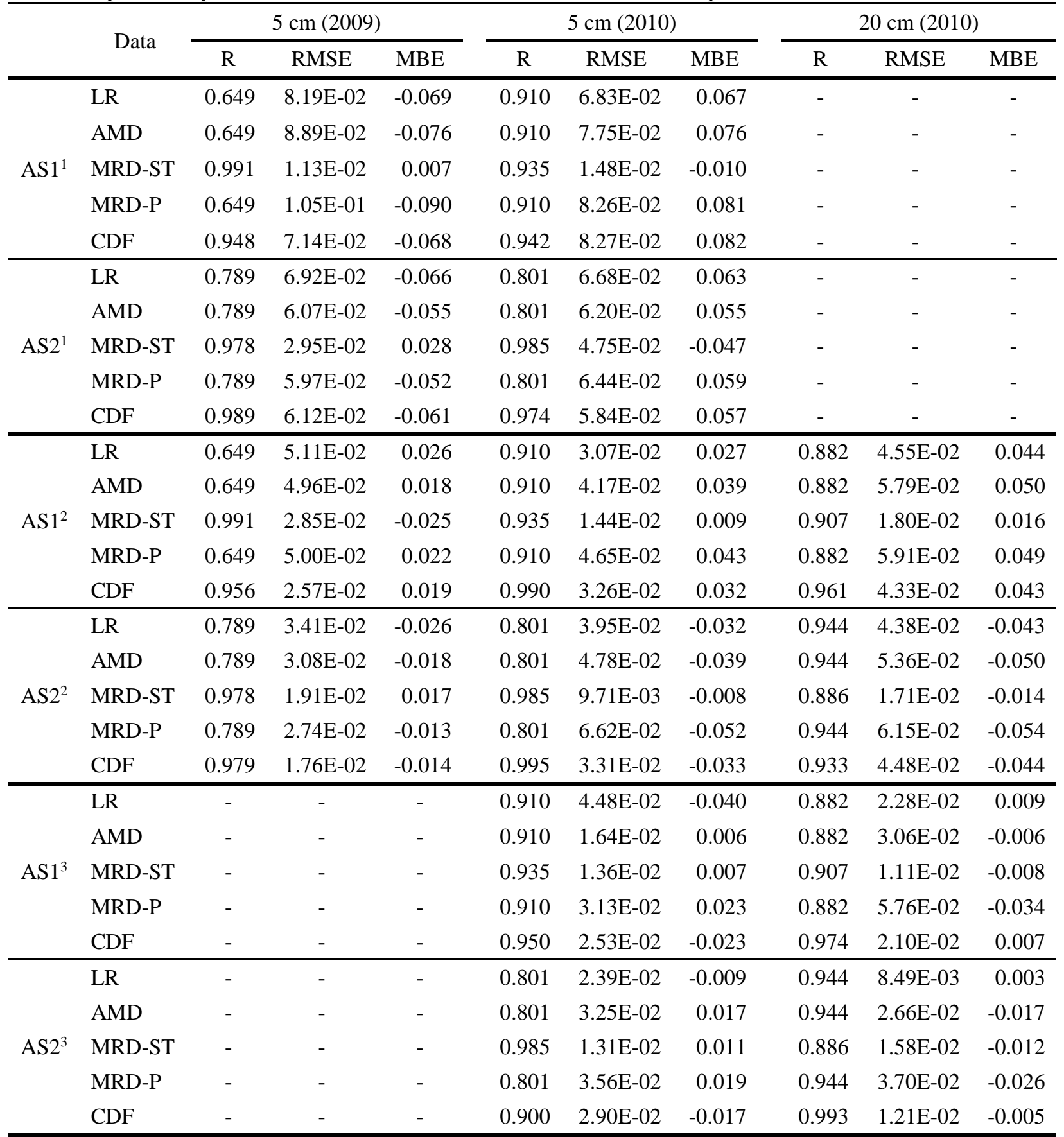

2: spatial transferability (AS1 vs. AS2)

3. vertical transferability $(5 \mathrm{~cm}$ vs. $20 \mathrm{~cm})$ 
1 Table 4. Performance of standard deviation estimation using the regression relationship between

2 the coefficient of variation and the field average.

\begin{tabular}{|c|c|c|c|c|c|c|c|}
\hline & & \multicolumn{3}{|c|}{$\begin{array}{c}\text { Coefficients of regression equation } \\
\qquad V=a \cdot \exp (\mathrm{b} \cdot \bar{\theta})\end{array}$} & \multirow[t]{2}{*}{$\mathrm{R}$} & \multirow[t]{2}{*}{ RMSE } & \multirow[t]{2}{*}{ MBE } \\
\hline & & $\mathrm{a}$ & $\mathrm{b}$ & $\mathrm{R}^{2^{*}}$ & & & \\
\hline \multirow{2}{*}{$\begin{array}{l}5 \mathrm{~cm} \\
(2009)\end{array}$} & AS1 & 0.428 & -3.641 & 0.862 & 0.432 & $3.60 \mathrm{E}-03$ & 0.000 \\
\hline & AS2 & 0.45 & -4.054 & 0.616 & 0.375 & $4.50 \mathrm{E}-03$ & 0.000 \\
\hline \multirow{2}{*}{$\begin{array}{l}5 \mathrm{~cm} \\
(2010)\end{array}$} & AS1 & 0.393 & -3.149 & 0.495 & 0.305 & $5.10 \mathrm{E}-03$ & 0.000 \\
\hline & AS2 & 1.146 & -5.774 & 0.721 & 0.443 & $8.90 \mathrm{E}-03$ & 0.000 \\
\hline \multirow{2}{*}{$\begin{array}{l}20 \mathrm{~cm} \\
(2010)\end{array}$} & AS1 & 21.08 & -14.93 & 0.928 & 0.931 & $3.50 \mathrm{E}-03$ & 0.000 \\
\hline & AS2 & 2.241 & -6.796 & 0.941 & 0.886 & $3.00 \mathrm{E}-03$ & 0.000 \\
\hline
\end{tabular}

$3 * \overline{\mathrm{R}^{2}}$ is the coefficient of determination resulted from the exponential regression between $\mathrm{CV}$ and field averages. 4 
1 Table 5. Performance of standard deviation estimation using the CDF matching.

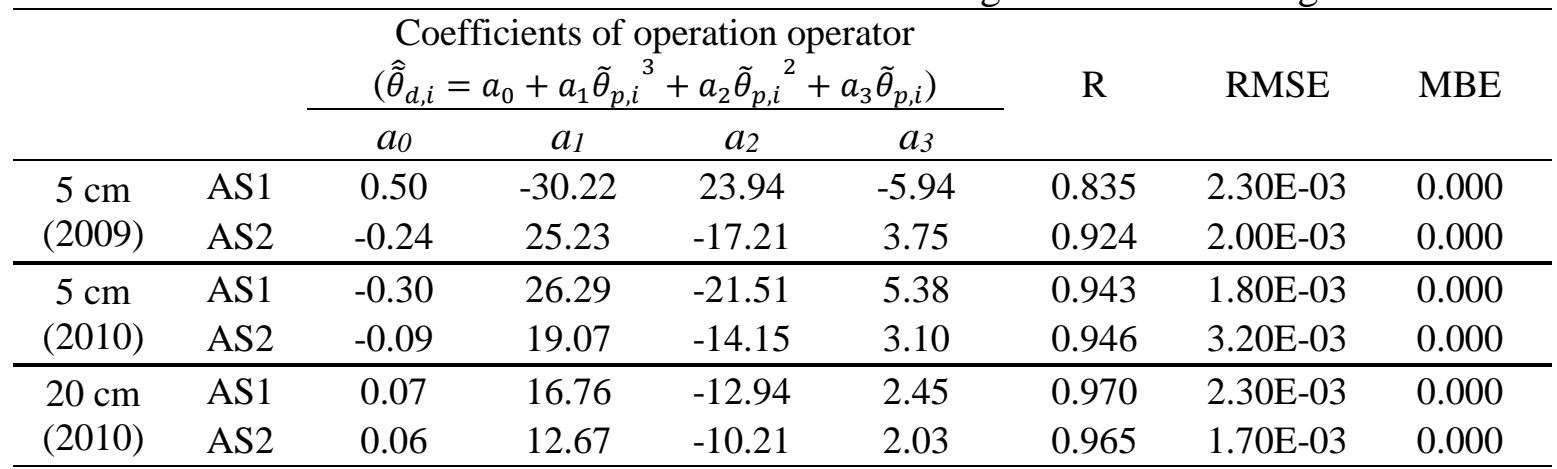

2

3

4 